\section{LA CUSTODIA COMPARTIDA EN LA PRÁCTICA JUDICIAL ESPAÑOLA: LOS CRITERIOS Y FACTORES PARA SU ATRIBUCIÓN*}

\author{
JOINT CUSTODY IN SPANISH JUDICIAL \\ PRACTICE: CRITERIA AND FACTORS FOR \\ ITS ATTRIBUTION
}

\author{
A GUARDA CONJUNTA NA PRÁTICA \\ JUDICIAL ESPANHOLA: CRITÉRIOS E \\ FACTORES PARA A SUA ALOCAÇÃO
}

\title{
RESUMEN
}

En el presente trabajo se hace un exhaustivo estudio jurisprudencial y doctrinal de los criterios, factores y circunstancias fácticas que valoran, especialmente, los Tribunales españoles a la hora de decidir respecto de la atribución de la custodia compartida de los hijos menores, tras la ruptura de la convivencia de sus progenitores. Después de exponer inicialmente unas ideas generales sobre los conceptos de patria potestad, visitas y custodia a tenor de la vigente legislación y Jurisprudencia española, se exponen seguidamente los criterios y factores que, con carácter general, se valoran por los Jueces a la hora de adoptar cualquier decisión relativa a los menores para pasar, finalmente, al análisis particular de los elementos fácticos más frecuentemente valorados por los Tribunales y Audiencias Provinciales dentro del proceso contencioso de familia, así como la interpretación que de los mismos viene haciendo el Tribunal Supremo. Todo ello sin olvidar el punto de vista de la psicología especializada.

\footnotetext{
* El presente articulo doctrinal es fruto de la inquietud intelectual del autor, surgido en el ámbito de su labor profesional.

a. Jurista, Magistrado-Juez sustituto, Diploma de Estudios Avanzados previos al Doctorado en Derecho Civil (Familia) por la UNED (2007). Consultor especialista en Derecho Matrimonial y de Familia. Ejercido el cargo de Abogado (1993-2002).
}

Cristobal Pinto Andrade ${ }^{a}$ cpinto3@hotmail.com Fecha de recepción: 25 de febrero de 2015 Fecha de revisión: 18 de junio de 2015 Fecha de aceptación: 23 de junio de 2015
MISIÓN JURÍDICA

Revista de Derecho y Ciencias Sociales Bogotá, D.C. (Colombia)

Colaboradores Externos Internacionales Núm. 9, Año 2015

Junio - Diciembre, pp. 143 - 175 


\section{PALABRAS CLAVE}

Custodia compartida, interés superior del menor, patria potestad, custodia, visitas, menor de edad, matrimonio, ruptura, convivencia

\begin{abstract}
In this article an exhaustive jurisprudential and doctrinal study is done, it is about criteria, factors and factual circumstances that are specially valued by the Spanish Courts when deciding about the attribution of joint custody of their underage children after the break in the cohabitation of their parents. In the beginning, after presenting some general ideas on the concepts of parental authority, visits and custody that comply with the current legislation and Spanish jurisprudence, then there is an explanation on the criteria and factors that generally are valued by Judges when adopting any decision in regards the minors. Finally it analyses factual elements more frequently valued by Courts and Provincial Courts in the family contentious process; also the interpretation that the Supreme Court does. All of these without leaving out the point of view of specialized psychology.
\end{abstract}

\section{KEY WORDS}

Joint custody, superior interest of the minor, parental authority, custody, visits, underage, marriage, break of cohabitation.

\section{RESUMO}

O presente trabalho é um exaustivo estudo doutrinário e jurisprudencial sobre os critérios, fatores e circunstâncias factuais que valorizam, especialmente, os tribunais espanhóis, na hora de se decidir quanto à guarda compartilhada das crianças, em decorrência da ruptura da convivência de seus pais. Depois de, inicialmente, apresentar algumas ideias gerais sobre o conceito de autoridade parental, visitas e custódia nos termos da vigente legislação e jurisprudência espanhola, são expostos os critérios e fatores que, usualmente, são valorizados pelos juízes na aplicação de qualquer decisão relativa à criança, e finalmente é feita a análise específica dos elementos factuais mais frequentemente avaliados pelos tribunais e audiências provinciais dentro do processo contencioso da família, bem como a interpretação que vem recebendo do
Supremo Tribunal. Tudo isto sem esquecer o ponto de vista da psicologia especializada.

\section{PALAVRAS-CHAVE}

Guarda compartilhada; interesse superior da criança; poder paternal; custódia; visitas; menor de idade; casamento; ruptura; convivência.

\section{METODOLOGÍA}

Se han recopilado, seleccionado, analizado y reseñado Sentencias de la Jurisprudencia emanada de la Sala Primera del Tribunal Supremo y las Audiencias Provinciales de España con incidencia en casos resueltos a partir de 2005 y particularmente desde 2009, cuando el Alto Tribunal comenzó a dictar una serie de resoluciones que venían a expresar con claridad su orientación interpretativa de la legalidad vigente.

\section{INTRODUCCIÓN}

Hasta la Ley 15/2005 de 8 de julio, por la que se modifican el Código Civil y la Ley de Enjuiciamiento Civil en materia de separación y divorcio (en adelante, Reforma 2005), el modelo seguido por la legislación civil en lo concerniente a las relaciones paterno filiales únicamente contemplaba el ejercicio conjunto de las funciones de guarda y custodia en los casos en que se conservaba la relación de convivencia entre ambos progenitores, dando lugar, en otro caso, a la atribución exclusiva en favor de uno o de otro, salvo muy escasas excepciones.

La Reforma del Código Civil en el año 2005 trató de dar cauce legal a los nuevos modelos de familia en los casos de crisis convivencial, la otra novedad importante fue el reconocimiento legal de la llamada "guarda y custodia compartida". En este punto, no obstante, el tiempo ha venido a demostrar que, más allá de este reconocimiento nominal, el legislador fue poco audaz -y hasta timorato- al abordar esta materia. En efecto, como se comprobará, tras la entrada en vigor de la Reforma 2005, la Jurisprudencia del Tribunal Supremo y la Doctrina vinieron haciendo eco de los evidentes defectos que la nueva norma presentaba en su literalidad, defectos que producían evidentes disfunciones en su aplicación práctica judicial. En realidad, como ha sido descrito muy gráficamente, la custodia 
compartida se fue abriendo paso a espaldas de la literalidad del propio Código Civil: Durante los últimos años, la Jurisprudencia y la práctica judicial han respaldado la normalización de la custodia compartida más allá de la ley vigente, y paralelamente, han ido deconstruyendo el esquema legal de la custodia exclusiva.

\section{CONSIDERACIONES GENERALES PREVIAS SOBRE LOS CONCEPTOS DE PATRIA POTESTAD, CUSTODIA Y VISITAS}

\subsection{La patria potestad}

A pesar de que no existe una definición legal de la patria potestad, viene siendo considerada en la Doctrina como la función (deber-facultad) que incumbe a los progenitores con relación a sus hijos menores de edad, con independencia de si existe matrimonio o no entre aquellos. En este sentido, podemos valorar los pronunciamientos de nuestra Jurisprudencia mayor. Así, la STS 1a de 25 de junio de 1994 definía la patria potestad como el "conjunto de derechos que la ley confiere a los padres sobre las personas y sobre los bienes de sus hijos no emancipados constituyendo a la par un conjunto de deberes que como inherentes a dicha institución, deben asumir y cumplir los padres respecto de sus hijos". La STS 1a de 9 de julio de 2002 señala que la patria potestad viene configurada en nuestro ordenamiento jurídico "como una función instituida en beneficio de los hijos, que abarca un conjunto de derechos concedidos por la Ley a los padres sobre la persona $y$ bienes de los descendientes en tanto son menores y no emancipados, para facilitar el cumplimiento de los deberes de sostenimiento y educación que pesa sobre dichos progenitores; constituye una relación central de la que irradian multitud de derechos y deberes, instituidos todos ellos, no en interés del titular, sino en el del sujeto pasivo". Por lo demás, la patria potestad es irrenunciable, imprescriptible e intransferible e indisponible por su titular y solo puede ser privado mediante resolución judicial debidamente fundada.

El Art. 154 C.C dispone que la patria potestad corresponde y se ejerce por ambos progenitores, de forma dual, compartida y conjunta o por uno solo con el consentimiento expreso o tácito del otro (Art. 156 C.C). Respecto a su contenido, el propio Art. 154 C.C detalla que, junto a la facultad de "tenencia en compañía" de los menores, la patria potestad incluye el ejercicio de otras facultades que bien pueden englobarse bajo la idea de su educación, salud y atención de los menores: "Velar por ellos, alimentarlos, educarlos y procurarles una formación integral, representarlos y administrar sus bienes".

Como se ve, de la propia interpretación del Art. 154 C.C se puede colegir que "Patria potestad" y "guarda y custodia" no son la misma cosa, pues entre ellas existe la relación del todo a la parte. Siendo esto así, en situaciones normales de convivencia de los progenitores, cuando los progenitores viven juntos y se relacionan con normalidad, la guarda y custodia sobre los hijos menores de edad se encuentra subsumida en la patria potestad que se ejerce conjuntamente por ambos progenitores.

\subsection{La guarda y custodia}

Como hemos visto, al enumerar el Art. 154 C.C los deberes y facultades de ambos progenitores que comprende la patria potestad, incluye "velar por ellos" y "tenerlos en su compañía". Es esta noción de "compañía" o "cuidado" la que precisamente ha determinado el concepto más general de la guarda y custodia: ésta comprendería aquellas funciones de la patria potestad que requieran de la convivencia ("cuidado y compañía") con el hijo menor.

Ocurre a veces que en situaciones distintas a la de convivencia normal de los progenitores, la guarda y custodia se separa de la patria potestad. Es entonces cuando tiene sentido indagar sobre el contenido de la guarda y custodia, que ya aparece disociada de la patria potestad. En estas situaciones, la guarda y custodia pasa de estar incluida en la patria potestad a separarse de ella. Es decir, pretender hallar el concepto de guarda y custodia únicamente cobra sentido cuando no existe convivencia entre los progenitores o ésta es, digamos, anormal. Estas situaciones "anormales" tienen distinta configuración:

a).- La primera se produce en el caso en que existe convivencia entre los progenitores pero se trata de una convivencia "anormal". A pesar de que los progenitores vivan juntos y la titularidad de la patria potestad pertenezca conjuntamente a ambos, es posible que el ejercicio de la guarda y custodia corresponda sólo a uno de ellos. El Art. 156 C.C contiene diversos supuestos de hecho y 
consecuencias jurídicas, que pueden afectar al ejercicio de la guarda y custodia de los hijos, ya que suponen excepciones al ejercicio conjunto de la patria potestad:

- Cuando han existido desacuerdos reiterados de los progenitores sobre aspectos importantes en el ejercicio de las funciones de la patria potestad. En estos casos, cualquier de los progenitores podrá acudir al Juez, quien decidirá lo necesario. (Art. 156 párrafo 2 C.C)

- Cuando un cónyuge esté incapacitado o imposibilitado transitoriamente para ejercer la guarda y custodia. En este grupo podemos incluir la segunda situación, la cual se produce cuando existe una separación de hecho entre los progenitores. En estas situaciones, la guarda y custodia será ejercida exclusivamente por el progenitor que convive con los hijos (Art. 156 párrafos 4 y 5 C.C).

b).- Una segunda situación es la que se deriva de la ruptura de la convivencia de los progenitores en el seno de los procesos judiciales que la disciplinan. En este caso, el Código Civil contiene unas normas específicas (señaladamente, los Arts. 90 a 96) donde aparecen reglas relativas a la atribución de la guarda de los hijos menores habidos en común en el matrimonio, las cuales se adoptarán en los procedimientos de nulidad, separación y divorcio matrimonial, sin dejar, por ello, de aplicarse los principios y normas generales de los Arts. $154 \mathrm{y}$ ss. C.C, relativas a la patria potestad, en tanto no entren en contradicción. Por demás, estas reglas se aplican de igual manera, por analogía, a los hijos nacidos en el seno de una pareja de progenitores que no esté unida en matrimonio, no casada.

Debe insistirse por tanto en que la distinción entre "guarda" y "patria potestad" cobra sentido, verdaderamente, cuando no son ambos progenitores los que conviven con el hijo, de tal manera que no es posible que -como se hace de manera natural a partir de la convivencialos dos realicen materialmente las funciones encomendadas en la patria potestad relativas al "cuidado" y "estar en su compañía”.

De esta forma, "patria potestad" resulta un término genérico y el de "guarda", específico. En este punto, debemos hablar del ejercicio de la "patria potestad" como concepto general, y la "guarda y custodia" como concepto especial, que aparece ante la realidad de la falta de convivencia de los hijos con cualquiera de sus progenitores.

La Jurisprudencia del Tribunal Supremo refrenda esta idea: El Alto Tribunal identifica la guarda y custodia con el deber de los padres de velar por sus hijos y tenerlos en su compañía (vid. STS 1a de 19 de octubre de 1983) y que a la postre viene a significar con quién va a convivir los hijos cuando se produce la ruptura de la convivencia de los progenitores.

Por demás, cabe señalar que no existe una definición legal de "guarda y custodia". Es bien cierto que en la legislación española existen referencias al vocablo, pero ni en el capítulo referente a los efectos de la ruptura matrimonial ni en relativo a las relaciones paterno-filiales, el Código Civil define ninguno de los términos objeto de análisis. Por su parte, la Doctrina española no ha dedicado demasiada atención al concepto de guarda, como distinto del de patria potestad.

\subsection{Los conceptos de "custodia" y "visitas"}

De acuerdo con el objeto del presente trabajo enfocaremos el tema de la guarda y custodia tras la ruptura de la convivencia de los progenitores. De este modo, y siguiendo la nomenclatura que podríamos denominar tradicional, la atribución de la "guarda y custodia" de los hijos menores supondría la designación -judicial o convencionaldel progenitor (llamado custodio) sobre el que recaerá el cuidado personal y directo de éstos, encargándose de su educación, control y convivencia cotidianos. Por contraposición al concepto de "guarda y custodia", se hablaría de atribución del "derecho de visita" a favor del progenitor no custodio, que vendría a referirse a "convivencia esporádica". De este modo, la guarda y custodia se identificaría con el cuidado y atención diario que se ejerce a través de la convivencia habitual con el menor.

No obstante, conviene detenerse a reflexionar sobre el sentido de las tradicionales nociones contrapuestas de "custodia" (como sinónimo de convivencia cotidiana con el menor) y "visitas" (como convivencia esporádica). Así llegaremos a comprender que en realidad la diferencia entre una y otra no sería más que, en todo caso, cuantitativa, es decir de mayor o menor cantidad 
de tiempo de convivencia con el menor, pero nunca cualitativa.

En efecto, fuera de casos excepcionales (como pudieran ser los regímenes supervisados judicialmente) en realidad no existe una diferencia cualitativa funcional entre la posición de "progenitor custodio" y de "progenitor visitante" pues ambas posiciones suponen las mismas facultades y deberes de cuidado, alimentación y educación (Art. 154.1 C.C) al menor por parte de estos progenitores. Es decir, el progenitor que no tiene atribuida la facultad de custodia del menor también ejerce de hecho esta facultad en los momentos en que los que está al cuidado de su hijo, ejercitando el "derecho de visita", por cuanto resulta indiscutible que en esos periodos de tiempo es él quien está llevando a cabo la tenencia, cuidado y protección del menor.. Desde un punto de vista cuantitativo, bien es verdad que los tiempos de convivencia con uno u otro progenitor puede ser comparativamente mayores o menores -y por eso, insistimos, puede existir una diferencia cuantitativa- e incluso que dentro de ese tiempo la labor de implicación parental puede ser de mayor o menor intensidad (p. ej. según exista pernocta o no con el menor, etc.) sin embargo, aun así, desde un punto de vista funcional y cualitativo ambos progenitores, "custodio" y "visitante", ejercen las mismas facultades de la responsabilidad parental de cuidado personal y directo en los tiempos en que conviven física y materialmente con el menor. En este sentido, si los periodos de tiempo durante los cuales uno de los progenitores ejerce el llamado "derecho de visita" resultan ser amplios -lo que cada vez es menos inusual-, es claro que la diferencia entre ambos conceptos tiende a diluirse aún más.

Por las razones expuestas en la Jurisprudencia, esta nomenclatura tradicional en los últimos tiempos ha venido siendo objeto de severas críticas.: la muy ilustrativa SAP Girona $1^{\mathbf{a}}$ de $\mathbf{1 0}$ de junio de 2011 (reiterada en las posteriores de 5 y 19 de octubre de 2011), aboga por la superación de los términos "custodia" y "visitas" de esta manera: "...Por lo tanto, se estima que debe superarse ya la terminología incorrecta de guarda y custodia, y de régimen de visitas, (...) que (...) puede llevar a interpretaciones erróneas, como ya hace el legislador catalán en la nueva regulación de Libro II del Código civil". También desde la Doctrina más autorizada se ha venido apuntado como recomendable la supresión de los términos "guarda y custodia" y "régimen de visitas" y su sustitución por el ejercicio de la responsabilidad parental por periodos de tiempo. Entre las ventajas que supone superar aquellos conceptos, debe destacarse que se evitaría el planteamiento del proceso de familia en términos de ganador y perdedor y coadyuvaría a una de las funciones que ha de perseguir el procedimiento de familia: la de pacificación del conflicto.

\subsection{La custodia compartida}

Teniendo siempre presente lo hasta aquí expuesto, es decir, que en realidad no existe una diferencia cualitativa entre la función de "custodia" y de "visita" sino en todo caso y a lo sumo, cuantitativa, de tiempo de convivencia, la practica judicial demuestra que, en situación de ruptura de la convivencia entre los progenitores, la guarda y custodia de los hijos menores puede ser atribuida:

- A uno de los progenitores, de manera individual y exclusiva, también llamada "custodia monoparental"

- A ambos progenitores, de forma alterna, también llamada "custodia compartida"

Debemos admitir que, al menos a día de hoy, la guarda de los hijos confiada a uno solo de los progenitores sigue siendo la medida que se puede considerar como la regla general en la práctica judicial. La única evolución jurisprudencial que pueda calificarse de significativa en este punto es la paulatina generalización de la custodia exclusiva, pero con amplios tiempos de régimen de visitas, para el progenitor no custodio.

\subsubsection{La custodia compartida: Denominación y concepto}

La custodia compartida constituye una relativa innovación que ha venido produciéndose en todo nuestro entorno cultural $^{1}$. En torno a la

1. Vid Estudio de Derecho comparado sobre la regulación de la custodia compartida, PEREZ-VILLAR APARICIO, Rosa. (coord.), Themis. Asociación de Mujeres Juristas, 2007. Disponible en http://www.amecopress.net/spip.php?article236. [consultado en mayo 2015]. 
denominación y conceptuación de la institución existe gran confusión, tanto en la práctica judicial como en la Jurisprudencia, la cual trataremos de desentrañar seguidamente.

Desde el punto de vista normativo, en el año 2005, a través de la Ley 15/2005 se procedió a modificar el Código Civil y la Ley de Enjuiciamiento Civil en materia de separación y divorcio. En concreto, se modificó el Art. 92 C.C y, específicamente, se procedió a regular la custodia compartida en sus apartados 5,7 y 8 . Literalmente el precepto completo, tras la Reforma del año 2005, disponía:

5. Se acordará el ejercicio compartido de la guarda y custodia de los hijos cuando así lo soliciten los padres en la propuesta de convenio regulador o cuando ambos lleguen a este acuerdo en el transcurso del procedimiento. El Juez, al acordar la guarda conjunta y tras fundamentar su resolución, adoptará las cautelas procedentes para el eficaz cumplimiento del régimen de guarda establecido, procurando no separar a los hermanos. (...)

7. No procederá la guarda conjunta cuando cualquiera de los padres esté incurso en un proceso penal iniciado por atentar contra la vida, la integridad física, la libertad, la integridad moral o la libertad e indemnidad sexual del otro cónyuge o de los hijos que convivan con ambos. Tampoco procederá cuando el Juez advierta, de las alegaciones de las partes y las pruebas practicadas, la existencia de indicios fundados de violencia doméstica.

8. Excepcionalmente, aun cuando no se den los supuestos del apartado cinco de este artículo, el Juez, a instancia de una de las partes, con informe favorable del Ministerio Fiscal, podrá acordar la guarda y custodia compartida fundamentándola en que sólo de esta forma se protege adecuadamente el interés superior del menor.

Como vemos, el actualmente vigente Art. 92 C.C incluye dos términos: "guarda conjunta" (apartado 7) y "guarda y custodia compartida" (apartado 5 y 8). Ambas denominaciones han sido objeto de críticas por la Doctrina, precisamente por no responder a la dinámica en que consiste: esta guarda ni es conjunta ni se comparte sino que se alterna entre los progenitores en el lugar de estancia y/o en el tiempo. Por ello, parece que lo más adecuado sería hablar de "custodia alterna, alternada, alternativa o sucesiva".

No obstante, hay que reconocer que la denominación "custodia compartida" es la que se suele utilizar en la práctica del foro y a nivel social aunque, insistimos, no es la más correcta pues no responde a la dinámica de la institución. En cualquier caso, por convención, es la que utilizaremos y da título al presente trabajo.

Más allá del nomen iuris interesa conocer el contenido que subyace bajo el término "custodia compartida". Si hemos de buscar un concepto de "custodia compartida" no lo encontraremos en el Código Civil. El fundamento teórico de la institución reside en la idea de que la separación o el divorcio ponen fin a la convivencia entre los progenitores pero no a los vínculos familiares; ello supone que los derechos y las responsabilidades de cada uno de los padres con respecto a sus hijos comunes, una vez sobrevenida la crisis convivencial, deben ser iguales a los derechos y responsabilidades que tenían con anterioridad. Este fundamento se corresponde con los conceptos de patria potestad y responsabilidad parental de los progenitores (Art. 154 C.C), la plena igualdad jurídica de las personas (Art. 14 C.E), de los cónyuges (Art. 66 C.C) y de los hijos ante la ley (Art. 39 C.E) $)^{2}$.

Según la Doctrina, sería aquel modelo de guarda y custodia en la que ambos progenitores se encargan de forma periódica o rotatoria del cuidado, atención y educación de los hijos menores ${ }^{3}$. En otro sentido, se señala que consiste en la alternancia de los progenitores en la posición de "guardador" y "visitador" (propios de la guarda exclusiva) que, en abstracto, les coloca en pie de igualdad y que garantiza el derecho del menor a ser educado y criado por sus dos progenitores a pesar de la ruptura de la pareja ${ }^{4}$. También incide en que se debe superar la idea que asocia la custodia compartida a igual reparto de tiempo de convivencia del menor

2. TOME CAMPUZANO, Herminia. "La custodia compartida. Doctrina jurisprudencial de las Audiencias Provinciales". EN: Aranzadi Civil, Tomo III, 2004, p. 2482.

3. PEREZ UREÑA, Antonio Alberto. "El interés del menor y la custodia compartida". EN: Revista de Derecho de Familia, no 26 2005, p. 275.

4. GUILARTE MARTIN-CALERO, Cristina. "Comentarios del nuevo Art. 92 C.C". EN: Comentarios a la Reforma de la separación y el divorcio. Ley 15/2005, Lex Nova, 2007, p. 156. 
con uno y otro progenitor, abogándose por fomentar la utilización de otros términos como el de guarda por periodos equitativos de tiempo ${ }^{5}$. En definitiva que se debe desterrar el mito de que la custodia compartida significa necesariamente un reparto por mitad de los períodos de convivencia del menor con cada uno de los padres.

Esta concepción de la custodia compartida como reparto de los periodos de convivencia de modo equitativo o equivalente, no necesariamente iguales, también es la recogida por la psicología especializada. Es un error muy frecuente la idea de muchos padres de que la custodia compartida implica que, únicamente, un reparto por mitades del tiempo de convivencia con los hijos, puede ser llamado como tal; en la distribución de los tiempos de convivencia habrá de buscarse la forma que más favorezca la implicación de ambos progenitores en la vida del hijo, de modo que la custodia compartida no será necesariamente un reparto salomónico, sino una distribución lo más equilibrada posible dentro de las circunstancias de cada familia ${ }^{6}$.

Se parte del hecho de que, en realidad, la guarda siempre es compartida por ambos padres, tanto en situaciones de normalidad matrimonial como en las de ruptura conyugal. Pero a ello ha de añadirse que la corresponsabilidad parental es un principio (consagrado en el Art. 92 C.C cuando señala que "la ruptura conyugal no extingue la responsabilidad parental') que informa la custodia compartida, junto a otras directrices, como la coparentalidad y la igualdad entre hombrey mujer ${ }^{7}$. Precisamente, la custodia compartida sería la figura que concreta la corresponsabilidad parental de la manera más acorde con todos los intereses familiares en conflicto tras la ruptura de los progenitores, pues supone un reparto de los derechos y deberes derivados del ejercicio de la patria potestad sobre los hijos, desterrando el tópico del progenitor custodio y responsable de su crianza, cuidado, atención y educación, y el del progenitor visitador .

5. VIÑAS MAESTRE, Dolores."Medidas relativas a los hijos menores en caso de ruptura: Especial referencia a la guarda". EN: InDret, julio 2012, p. 9

6. AGUILAR, José Manuel. Tenemos que hablar, Editorial Taurus, 2008, p. 152

7. LATHROP, Fabiola. "Custodia compartida y corresponsabilidad parental. Aproximaciones jurídicas y sociológicas". EN: Diario La Ley, № 7206, Sección Doctrina, 29 Junio 2009.

8. SERRANO CASTRO, Francisco. "Hacia un nuevo modelo de corresponsabilidad parental". EN: Revista Iuris, Noviembre 2010, p. 25.
En la Jurisprudencia se destaca que, cuando se alude a la custodia compartida, nos estamos refiriendo a un sistema de alternancia o reparto de tiempos y lugares de estancia de los hijos con cada uno de sus padres, o sea, cuando se resuelve sobre la custodia compartida, lo que se está decidiendo es con cuál progenitor y donde vivirá el menor en cada momento. Se dice que se trata de una modalidad de ejercicio de la responsabilidad parental, tras la crisis de la pareja, en la que tanto el padre como la madre están capacitados para establecer una relación viable entre ellos, basada en el respeto y en la colaboración, con el objeto de facilitar a los hijos comunes la más frecuente y equitativa comunicación con ambos progenitores, y de distribuir de forma justa y proporcional la atención de las necesidades materiales de los hijos, con la previsión de un sistema ágil para la resolución de los desacuerdos que puedan surgir en el futuro (SAP Barcelona 12 $2^{\mathrm{a}}$ 9.03.2007).

Se insiste en relacionar la institución con la idea de coparentalidad o corresponsabilidad parental como la más adecuada para el desarrollo del menor, debiendo traerse a colación, como exponente de este último criterio la SAP Barcelona 18 19 $^{\mathrm{a}}$ de 11 de febrero de 2009, expone muy acertadamente que

(...)en principio nada hay mejor para los hijos que poder conseguir que ambos progenitores, padre y madre, en igualdad de condiciones y respetándose mutuamente, ejerzan de forma compartida la custodia de sus hijos, pues a fin de cuentas esta sería la situación ideal y más parecida a la convivencia familiar que mitiga los efectos más negativos de la ruptura de la unidad familiar al posibilitar que los hijos se pueden sentir más seguros arropados por ambos progenitores(...).

Tratando de profundizar en los aspectos fundamentales de la institución, la muy ilustrativa SAP Girona $1^{\mathrm{a}}$ de 10 de junio de 2011 (reiterada en las posteriores de 5 y 19 de octubre de 2011), señala que este tipo de guarda lo que significa es que "ambos progenitores tienen los mismos derechos y las mismas obligaciones respecto de los hijos, lo cual no significa o supone que los periodos de estancias que los padres deban tener con sus hijos sean igualitarias" (negrilla fuera del original).

De modo que la custodia compartida podría definirse como una forma de atribución 
del ejercicio de la función de convivencia y cuidado directo de los menores, en favor de ambos progenitores tras la ruptura de éstos, por periodos de alternancia equitativos, más que igualitarios, y para cuya adecuada comprensión debe prevalecer la idea de corresponsabilidad parental, debiendo ponderarse tanto el elemento cuantitativo (en cuanto a tiempo, frecuencia y regularidad del cuidado del menor) como el cualitativo (cuánto tiempo, cómo, con qué contenido) referido en la implicación real y efectiva del progenitor en la crianza del menor. Aunque la cantidad de tiempo es importante, lo esencial es la coparentalidad. En síntesis, lo característico de la custodia compartida, más que una cierta igualdad de tiempos de cuidado -que también lo es- reside en la real, efectiva y equitativa implicación de ambos progenitores en el cuidado del hijo menos tras su ruptura, en su doble vertiente: material y emocional.

Como muy agudamente señala la STSJ Cataluña $1^{\text {a }}$ de $\mathbf{3 1}$ de julio de 2008 lo cierto es que bajo la denominación equívoca de "custodia compartida" pueden hallar amparo muchas $\mathrm{y}$ diversas situaciones de convivencia de los hijos con sus progenitores -partida, repartida, rotativa, alterna, conjunta-, que supongan un reparto no necesariamente igual del tiempo de convivencia con cada uno de los padres y/o de las tareas o funciones que en relación con su cuidado diario cada uno de ellos se obligue a asumir, en razón a muy diversos factores (la diferente edad de los niños, su comodidad y confort, su aprovechamiento escolar, sus problemas evolutivos particulares, el horario laboral y la disponibilidad efectiva de los padres, etc.).

En efecto, la Jurisprudencia insiste en esta concepción cuando señala que por custodia compartida no cabe entender que los hijos pasen a vivir con uno y otro progenitor repartiéndose por periodos iguales, sino que todas las concepciones doctrinales sobre esta cuestión giran en torno a un mayor grado de implicación del cónyuge no conviviente en las cuestiones relativas al cuidado y educación de los hijos, con una participación mucho más activa que la contemplada hasta ahora, no limitándose a ser mero receptor pasivo de la prole en el domicilio propio los fines de semana alternos y los periodos vacacionales (SAP Toledo 1a 2.02.2005). En este sentido la Jurisprudencia se encarga de poner de relieve que en una "custodia por periodos repartidos" resulta palmario que el contenido semántico del verbo "repartir" es muy distinto del de "compartir". (SAP Barcelona 12 20.12.2006, SAP Barcelona 12a 25.07.2007, SAP Barcelona 12aㅗ 16.10.2007)

\subsubsection{La configuración de la custodia compartida en el Código Civil español}

La aportación fundamental de la Ley 15/2005 en lo relativo a la llamada "custodia compartida" consistió en hacer visible esta modalidad de ejercicio de la patria potestad. Sin embargo, junto a esta señalada virtud, los calificativos que mereció, por parte de la Doctrina, la regulación de la guarda compartida contenida en el Art. 92.C.C fueron desde "entelequia" e "imposible" ${ }^{9}$ hasta "laberíntica"10 o "realidad excepcional"11. Desde la promulgación de la nueva norma, la Doctrina y la praxis judicial pusieron de manifiesto las dificultades que presentaba la instauración judicial de la custodia compartida por los evidentes exigentes requisitos sustantivos y procesales; la práctica judicial, la Jurisprudencia del Tribunal Supremo y la Doctrina pronto se hicieron eco de estos evidentes defectos que la norma presentaba en su literalidad, defectos que producían evidentes disfunciones en su aplicación práctica judicial. Las dificultades se presentan, en principio, desde distintos frentes:

A. Configuración procesal: Su solicitud de parte en el proceso contencioso. Resulta absolutamente necesaria la solicitud de la medida de custodia compartida por -al menos- una de las partes procesales, lo que solo podía producirse en la tramitación del procedimiento contencioso principal del Art. 770 LEC o de Medidas Provisionales previas (Art. 771 LEC) o coetáneas (Art. 773 LEC). Frente al principio general que impera en el resto de medidas relativas a los menores, en el Código Civil, la atribución de la custodia compartida, según la Ley 2005 y en

9. PEREZ MAYOR, Adrián. "La entelequia de la custodia compartida o alterna" EN: Revista Jurídica de Cataluña", № 3, 2007

10. IBANEEZ VALVERDE, Vicente. "El laberinto de la custodia compartida. Claroscuros de un solo nombre con varios significados" EN: Boletín de Derecho de Familia, núms. 40 y 41, noviembre y diciembre de 2004, El Derecho.

11. RIVERA ALVAREZ, Joaquín. "La custodia compartida impuesta por el Juez:una realidad excepcional en las crisis matrimoniales" EN: Acciones e Investigaciones Sociales, № 1 Ext, 2006 p. 16. 
proceso contencioso, regía absolutamente el principio rogatorio. El Tribunal Supremo tampoco se ha sustraído a pronunciarse sobre la cuestión con rotundidad: En la STS 1a $\mathbf{a}$ de 19 de abril de 2012 se destaca que

Un requisito esencial para acordar este régimen es la petición de uno al menos de los progenitores; si la piden ambos, se aplicará el párrafo quinto del artículo 92 del Código Civil, y si la pide uno solo y el juez considera que, a la vista de los informes exigidos en el párrafo octavo de dicho precepto legal, resulta conveniente para el interés del niño, podrá establecerse este sistema de guarda. El Código civil, por tanto, exige siempre la petición de al menos uno de los progenitores, sin la cual no podrá acordarse. En consecuencia y en este caso concreto, dado que ninguno de los progenitores ha pedido la guarda y custodia compartida no se ha infringido el artículo 92 del Código Civil.

La Doctrina siempre ha venido criticando que cuando en el proceso, solo una de las partes solicita la custodia compartida, quedará de manifiesto la inicial falta la voluntad de la otra de las partes. Es un contrasentido en sí mismo que el Juez imponga a un progenitor que ejerza una custodia que luego se va a "compartir". La noción de custodia compartida parece exigir una predisposición para su viabilidad que no casa muy bien con su inicial imposición judicial.

B. La necesidad del informe favorable del Ministerio Fiscal. La exigencia de este informe favorable vino constituyendo, sin lugar a dudas, el punto más controvertido del precepto. No se trata solamente de que se requiera que el fiscal emita un informe, sino que además éste ha de ser favorable. Resulta evidente que tal necesidad limita la facultad decisoria del juez, con el agravante de que dicho requisito no es necesario cuando el juez decreta la custodia en exclusiva.

En su redacción inicial, el Art. 92.8 C.C exigía que el Informe que preceptivamente debe emitir el Ministerio Fiscal debía ser "favorable" a la custodia compartida. Como se expuso antes, la exigencia de este Informe favorable constituía, sin lugar a dudas, el punto más controvertido de aquel precepto. En esta cuestión existieron desde el principio posiciones radicales que apuntaban a que el precepto debía de interpretarse restrictivamente, de modo que un Informe negativo no puede vincular de ninguna manera la decisión judicial ${ }^{12}$. Otros, en parecida línea, abogaban por una interpretación sistemática, en el sentido de reconducirla limitativamente a entender exigible un Informe favorable del Fiscal, que auxiliara la decisión judicial y, en caso de que sea desfavorable, exigirá del Juez reforzar sus argumentos para imponer la medida más adecuada y beneficiosa para el menor ${ }^{13}$. En esta tesitura, algunos Tribunales interpretaron de una manera laxa el requisito, entendiendo como no favorable tan solo la oposición expresa y clara por parte del Ministerio Fiscal, de tal manera que si el Fiscal no informa o no se opone al recurso, se entiende que es favorable (SAP Granada 5a de 15 de abril de 2011).

Criticaba con dureza la Doctrina que no era de recibo que el Juez, simplemente por razones formales (la falta del Informe favorable del Fiscal), no pudiese adoptar esta medida ${ }^{14}$. Finalmente, como elemento de agravio comparativo, las leyes autonómicas que, a partir del año 2005, comenzaron a regular esta materia (Aragón, Cataluña, Navarra y Valencia) tenían en común, entre otros extremos, la no exigencia del informe favorable del Ministerio Fiscal. En síntesis, la cuestión estaba lejos de ser pacífica por lo que se fueron planteando por distintos Juzgados y Tribunales diferentes Cuestiones de Constitucionalidad del Art. 92.8 C.C ante el Tribunal Constitucional, en lo relativo al requisito del Informe favorable del Ministerio Fiscal. Finalmente, uno de ellos, el planteado por la Sección 5o de la Audiencia Provincial de Las Palmas por Auto de 13 de septiembre de 2006, fue resuelta por STC del Pleno no 185/2012, de 17 de octubre de 2012 y se declara inconstitucional y nulo el inciso "favorable" contenido en el Art. 92.8 del Código Civil, según redacción dada por la Ley 15/2005.

C. Configuración legal en proceso contencioso como medida excepcional. El uso de los adverbios "Excepcionalmente" y que "solamente" de esa manera se protegiera el interés

12. MONTERO AROCA, Juan. "Comentarios al Art. 92. La guarda y custodia compartida". EN: Separación y Divorcio tras la ley 15/2005, Tirant Lo Blanc, 2007, p. 138

13. RIVERA ALVAREZ, Joaquín. "La custodia compartida impuesta...," op. cit. p. 14

14. Ibíd, p. 14 
del menor, revelaban que, prima facie, el legislador encaraba la cuestión con extraordinarias cautelas, además de poner de manifiesto que la atribución de la custodia compartida a solicitud de una sola parte se presentaba, normativamente, como una anormalidad o rareza.

Desde una perspectiva de política legislativa, para resolver el conflicto existente entre los progenitores sobre la custodia de los menores, cuando sus progenitores se separan o divorcian, básicamente caben articular tres fórmulas legales: (i) Configuración de la custodia monoparental como preferente y la custodia compartida como excepcional; (ii) configuración de la custodia compartida como preferente y custodia monoparental como excepcional; (iii) sistema de libre determinación judicial del tipo de custodia donde, en caso de conflicto entre los progenitores, es el Juez quien, sin previas limitaciones o preferencias, debe acordar, razonadamente, el régimen de custodia que considere más beneficioso para los hijos menores.

La literalidad del derogado Art. 92.8 C.C parece alinearse con la primera de las opciones legislativas cuando decía, para el caso de solicitud unilateral de custodia compartida, que "Excepcionalmente... deberá fundamentarse su decisión en que sólo de ese modo se protege adecuadamente el interés superior del menor". El precepto utilizaba el adverbio "excepcionalmente" con el que se califica la posibilidad del Juez de acordar la custodia compartida. De este modo, y desde una lectura literal de la norma, podía llegar a colegirse una configuración normativa "excepcional" de la medida de la custodia compartida, percepción a la que parecía coadyuvar que se requería que "sólo de este modo" (esto es, con la adopción de la custodia compartida) se protegía el interés del menor; que "sólo" se proteja el interés del menor con la custodia compartida, significaba que si los padres no estaban de acuerdo la adopción de esta medida quedaba condicionada a que no existiera ninguna otra alternativa, es decir que el menor no estaría bien conviviendo únicamente con su madre, ni tampoco conviviendo sólo con su padre. Así formulado, el antiguo Art. 92.8 C.C adolecía de cierta contradicción puesto que si se protege el interés del menor si convive con ambos, también se protegería conviviendo con uno de ellos, con lo cual la custodia compartida, como única medida de protección del menor, por definición nunca podría alcanzarse.
En este contexto, desde el año 2009, el Tribunal Supremo fue dictando una serie de Sentencias relativas a la custodia compartida. En estas resoluciones, junto con consideraciones relativas al fondo del asunto y sobre cuestiones generales como el interés superior del menor, se contienen pronunciamientos, en ocasiones "obiter dicta", que nos ayudan a destilar la interpretación que hace el Alto Tribunal sobre regulación y configuración legal de la custodia compartida contenida en el Art. 92.8 C.C y, específicamente, en punto a esa presunta e hipotética "excepcionalidad" y el valor que debe otorgarse a esta expresión. Desde las primeras resoluciones dictadas desde aquella fecha el Alto Tribunal enfatiza que ningún régimen de guarda de los menores presenta ni preferencia ni primacía pero tampoco excepcionalidad.

En la STS 1a de 7 de julio de 2011 se dice que:

(...) la redacción de dicho artículo no permite concluir que se trate de una medida excepcional, sino que al contrario, debería considerarse la más normal, porque permite que sea efectivo el derecho que los hijos tienen a relacionarse con ambos progenitores, aun en situaciones de crisis, siempre que ello sea posible y en tanto en cuanto lo sea.

Más tarde, en la STS $1^{\text {a }}$ de $\mathbf{2 2}$ de julio de 2011 (reiterada en la STS 1aㅡ de 25 de mayo de 2012) se viene a explicar la interpretación que ha de darse al adverbio "excepcionalmente" el Art. 92.8 C.C:

La excepcionalidad a que se refiere el inicio del párrafo 8, debe interpretarse, pues, en relación con el párrafo cinco del propio artículo que admite que se acuerde la guarda y custodia compartida cuando así lo soliciten ambos progenitores o uno con el acuerdo del otro. Si no hay acuerdo, el Art. 92.8 CC no excluye esta posibilidad, pero en este caso, debe el Juez acordarla "fundamentándola en que solo de esta forma se protege adecuadamente el interés superior del menor". De aquí que no resulta necesario concretar el significado de la "excepcionalidad", a que se refiere el Art. 92.8 CC, ya que en la redacción del artículo aparece claramente que viene referida a la falta de acuerdo entre los cónyuges sobre la guarda compartida, no a que existan circunstancias específicas para acordarla.

Posteriormente, en la STS $1^{\text {a }}$ de 10 de enero de 2012 con rotundidad señala el Alto Tribunal: 
Hay que precisar que todo régimen de custodia tiene sus ventajas y sus inconvenientes y que la primacía del sistema de custodia compartida que destaca la parte recurrente no es tal, pues lo que ha de primar es aquel sistema que en el caso concreto se adapte mejor al menor y a su interés, no al interés de sus progenitores, pues el sistema está concebido en el artículo 92 como una forma de protección del interés de los menores cuando sus progenitores no conviven, no como un sistema de premio o castigo al cónyuge por su actitud en el ejercicio de la guarda (STS de 11 de marzo de 2010 RC 54/2008; STS de 7 de julio de 2011, RC 1221/2010 ; STS de 21 de febrero de 2011, RC núm. 1886/2008, entre otras).

Finalmente, la STS 1a de 29 de abril de 2013 sistematizó la posición del Alto Tribunal sobre la configuración legal de la custodia compartida en el Código Civil vigente declarando, como doctrina jurisprudencial, que la interpretación de los Arts. 92.5,6 y 7 C.C debe estar fundada en el interés de los menores quienes van a quedar afectados por la medida que se deba tomar, que se acordará cuando concurran criterios tales como la práctica anterior de los progenitores en sus relaciones con el menor y sus aptitudes personales; los deseos manifestados por los menores competentes; el número de hijos; el cumplimiento por parte de los progenitores de sus deberes en relación con los hijos y el respeto mutuo en sus relaciones personales; el resultado de los informes exigidos legalmente, $y$, en definitiva, cualquier otro que permita a los menores una vida adecuada, aunque en la práctica pueda ser más compleja que la que se lleva a cabo cuando los progenitores conviven. Se reitera que la redacción del Art. 92 C.C no permite concluir que se trate de una medida excepcional, sino que al contrario, habrá de considerarse normal e incluso deseable, porque permite que sea efectivo el derecho que los hijos tienen a relacionarse con ambos progenitores, aún en situaciones de crisis, siempre que ello sea posible y en tanto en cuanto lo sea.

\section{LOS CRITERIOS PARA LA DETERMINACIÓN JUDICIAL DEL MODELO DE CUSTODIA DE LOS HIJOS MENORES TRAS LA RUPTURA DE LA CONVIVENCIA DE LOS PROGENITORES}

A la hora de adoptar las decisiones judiciales en conflictos o situaciones donde se hallen involucrados menores de edad y, particularmente, en la determinación judicial del modelo de custodia de los hijos menores tras la ruptura convivencial de los progenitores, nuestro sistema jurídico se articula en torno a dos ideas: (i) El principio general del interés superior de los hijos menores (bonum filii, favor filii, favor minoris) y (ii) Una amplísima discrecionalidad judicial en la determinación de dicho interés. Dicho en otras palabras, la norma parte de una cláusula general o concepto jurídico indeterminado ("interés superior del menor") dejando en manos del juzgador su determinación en el caso concreto, para lo que cuenta con una amplia discrecionalidad.

En la materia de la determinación judicial del modelo de custodia de los hijos menores cuando sus progenitores no conviven, hoy, en España, y a diferencia de épocas pretéritas, el Código Civil no señala un criterio legal fijo para dicha determinación; el ordenamiento civil señala un principio general o concepto jurídico indeterminado, el "interés superior del menor", interés cuya determinación judicial es variable en cada caso concreto. El principio general del "interés superior del menor", como eje en torno al cual debe girar la determinación judicial del modelo de custodia de los hijos menores cuando sus progenitores no conviven, en realidad tampoco está explicitado actualmente con claridad en el Código Civil. Aunque en el tenor literal del Art. 92 C.C, solamente en dos apartados - el $4^{\circ} \stackrel{\circ}{ }$, relativo a la patria potestad y el $8^{\circ}$, relativo precisamente a la custodia compartida -, se aludía al "beneficio del hijo", resultaba obvio que esa misma ha de ser la regla de actuación en los apartados 5, 6 y 7. La Doctrina ${ }^{15}$ siempre sugirió que hubiera sido más conveniente proclamar con carácter general el reconocimiento del favor filii como criterio rector de todas las actuaciones relativas a los hijos menores, sin necesidad de tener que situarlo (o interpretar que lo está) al regular cada una de las medidas. No obstante, y a pesar de esta falta de proclamación, parece claro que, al tratarse de un principio general no tiene mayor relevancia (más que la meramente sistemática) la falta de referencia al mismo en determinados aspectos.

15. TENA PIAZUELO, Isaac. "La guarda compartida compartida y las nuevas relaciones de familia". EN: Revista Aequalitas, № 18, Enero-junio 2006, p. 38; SEISDEDOS MUIÑO, Ana. "Las medidas relativas en los procesos de divorcio y separación matrimonial: primera aproximación al nuevo texto del Código Civil (Ley 15/2005)". EN: Aranzadi Civil, № 3, 2005, p. 2399 
Insistimos: para la determinación del modelo de custodia la norma señala y alude simplemente al "interés superior del menor", dejando en manos del Juez sus determinación en cada caso concreto.

Cuestión muy diferente es que, en la práctica judicial, la Jurisprudencia haya venido utilizando a lo largo del tiempo una relación de factores, indicadores, circunstancias $y$ elementos fácticos que deben ser valorados y ponderados por el Juez para llegar a su convicción. El diccionario de la Real Academia de la Lengua Española define "criterio" como "norma para conocer la verdad". Pues bien, ha de insistirse en que, en puridad y sentido estricto, estos elementos o factores no son criterios legales sustantivos de determinación del interés superior del menor sino, simplemente, elementos de valoración para llegar a tal determinación. En efecto, es constatable en la Jurisprudencia, en algunos casos explicitados de manera expresa, como la presencia de diversos factores, indicadores, circunstancias $y$ elementos fácticos que pueden ser valorados y ponderados judicialmente para llegar a su convicción, factores que, en realidad, no son sino la consagración legal de los que la práctica judicial y la Jurisprudencia, ha venido utilizando a lo largo del tiempo. ¿Qué factores, circunstancias y elementos fácticos son éstos?

En este punto, el Código Civil simplemente dispone que: "El Juez deberá valorar la relación que los padres mantengan entre sí y con sus hijos, como criterio para determinar la idoneidad con el régimen de guarda". (Art. 92.6 C.C). Como acertadamente señala la Doctrina ${ }^{16}$, en realidad estas dos circunstancias no son las únicas que debía evaluar el Juez a la hora de tomar la decisión; tendría que sopesar también muchas otras circunstancias que en el precepto no se mencionan: edad, situación laboral, ubicación de los domicilios, estado de salud, voluntad de los menores, situación económica etc.... La enumeración, se dice, es incongruente, incompleta y a la vez, redundante.

En este sentido, ya alguna resolución de la Jurisprudencia menor ha venido a destacar los factores, circunstancias o elementos fácticos

16. SEISDEDOS MUIÑO, Ana., op. cit, p. 2402 concurrentes a valorar que la práctica judicial ha ido consagrando para la determinación de alguna de las modalidades de custodia posibles (SAP Barcelona 12aㅡ. 20.12.2006):

a). La disponibilidad de tiempo de uno y otro progenitor para dedicarlo a los hijos;

b). El aseguramiento de la estabilidad del menor en relación con la situación precedente, procurando la continuidad del entorno, las relaciones con la familia amplia, el colegio, los amigos o la ciudad o barrio;

c). La ponderación de cuál de los progenitores ofrece mayor garantía para que la relación con el otro progenitor se desarrolle con normalidad;

d). El rol de dedicación a los hijos de uno y otro progenitor en la etapa de convivencia anterior a la separación;

e). La garantía del equilibrio psíquico del menor, para que no se vea afectado por desequilibrios graves que afecten a uno de los progenitores;

f). La precaución de que quede deslindada la idoneidad de la custodia, con el afán por la obtención de réditos materiales indirectos, no confesados, como el uso de la vivienda o la percepción de pensiones.

Modernamente, el propio Tribunal Supremo, con motivo de la caracterización de la custodia compartida -como tendremos ocasión de comprobar más adelante-, tampoco se ha sustraído a reseñar (a partir de la STS 1a de 8 de octubre de 2009 y fijada como doctrina jurisprudencial en la STS 1 a de 29 de abril de 2013) los elementos fácticos más destacables a valorar judicialmente a la hora de decantarse por un sistema de custodia u otro.

\section{LOS FACTORES ESPECÍFICOS QUE SON VALORADOS EN LA PRÁCTICA JUDICIAL PARA LA ATRIBUCIÓN DE LA CUSTODIA COMPARTIDA}

Cuando se trata de valorar la atribución de la custodia compartida, la Jurisprudencia y la práctica judicial, nos muestran que se ponderarán especialmente algunos factores, indicadores, elementos y circunstancias fácticas. 
Como ya se explicó más arriba, el ordenamiento jurídico y el Código Civil, al proclamar el principio general del "interés superior del menor" deja en manos del criterio discrecional del Juez su determinación en cada caso concreto. En otras palabras, en estas situaciones, la norma no nos ofrece la solución directa sino que ésta debe ser buscada por el Juez acudiendo a criterios de valor o de experiencia valorando las circunstancias, indicadores, factores o elementos fácticos concurrentes en cada caso, factores que pueden ser destilados de la Jurisprudencia.

En este sentido, y en relación con la custodia compartida, los psicólogos ${ }^{17}$ y la propia Jurisprudencia traen habitualmente a colación el listado de los requisitos o condiciones materiales y personales cuya presencia, de modo orientativo, facilita $o$ favorece el establecimiento de este tipo de custodia. Dentro de la Jurisprudencia menor, proveniente de las Audiencias Provinciales, puede citarse en este sentido la ya lejana SAP Alicante $6^{\mathbf{a}}$ de 29 de diciembre de 2004 que señalaba los siguientes: Muy bajo nivel de conflicto entre los progenitores, buena comunicación y cooperación entre ellos, residencias cercanas o geográficamente compatibles, rasgos de personalidad y carácter de los hijos y los padres compatibles, estilos educativos de los progenitores similares 0 compatibles, edad de los menores y número de hermanos que permitan su adaptación, cumplimiento por los progenitores de las obligaciones económicas, respeto mutuo por ambos progenitores; que no haya excesiva judicialización de la separación, existencia de un vínculo afectivo de los niños con ambos padres y que acepten este tipo de custodia, que ambos progenitores estén de acuerdo con la alternativa de custodia compartida.

Particularmente, en relación a los factores y circunstancias fácticas a valorar judicialmente, más recientemente la SAP Barcelona 12 ${ }^{a}$ de 30 de noviembre de 2012 ha puesto de manifiesto que, para el establecimiento judicial de un sistema de guarda y custodia compartida, se valorarán aspectos como que entre los progenitores no existan desavenencias respecto al sistema y principios de educación del hijo menor, que ambos estén

17. POUSSIN, Gerard., LAMY, Anne., Custodia compartida, Espasa práctico, 2004, p. 53-59 capacitados para ejercer las funciones de guarda, e, incluso, su capacidad para alcanzar acuerdos en beneficio del menor, la existencia de fuertes vínculos afectivos del menor con ambos progenitores y que éstos sean personas equilibradas, responsables, respetuosas y preocupadas por el bienestar de su hijo, que los progenitores tengan horarios compatibles con los cuidados del menor, así como ayuda de la familia extensa, la proximidad de los domicilios y acceso al colegio, y que tenga habitación propia en ambos domicilios.

La posterior SAP Barcelona $12^{\mathrm{a}}$ de 27 de febrero de 2013 también hizo un interesante compendio de este conjunto de circunstancias y factores que se deben ponderar a la hora de establecer la custodia compartida que serían, entre otros, la disponibilidad de tiempo de uno y otro progenitor para dedicárselo a los hijos, el aseguramiento de la estabilidad de los menores en relación con la situación precedente, procurando la continuidad del entorno, familia amplia, colegio, amigos o ciudad o barrio, la ponderación de cuál de los progenitores ofrece mayor garantía para que la relación con el otro progenitor se desarrolle con normalidad, el rol de dedicación a los hijos de uno y otro progenitor en la etapa de convivencia anterior a la separación, la garantía del equilibrio psíquico de los menores, para que no se vean afectados por desequilibrios graves de alguno de los progenitores, y que quede deslindada la idoneidad de la custodia, con el afán por la obtención de réditos materiales, como el uso de la vivienda o la percepción de pensiones.

Desde la Jurisprudencia mayor, es decir, desde el Tribunal Supremo, en recientes resoluciones, se ha venido a recoger una serie de factores relativos a la interpretación de lo que significa "el interés del menor"; y en concreto, respecto a los criterios o parámetros a tener en cuenta para justificar el interés del menor a la hora de adoptar la custodia compartida. La interesantísima STS $1^{\text {a }}$ de 8 de octubre de 2009, resolución paradigmática en muchos sentidos, pone de manifiesto que

del estudio del derecho comparado se llega a la conclusión que se están utilizando criterios tales como la práctica anterior de los progenitores en sus relaciones con el menor y sus aptitudes personales; los deseos manifestados por los menores competentes; el número de hijos; el cumplimiento por parte de los progenitores de sus 
deberes en relación con los hijos, el respeto mutuo en sus relaciones personales y con otras personas que convivan en el hogar familiar; los acuerdos adoptados por los progenitores; la ubicación de sus respectivos domicilios, horarios y actividades de unos y otros; el resultado de los informes exigidos legalmente, $y$, en definitiva, cualquier otro que permita a los menores una vida adecuada en una convivencia que forzosamente deberá ser más compleja que la que se lleva a cabo cuando los progenitores conviven.

En concreto, según pone de manifiesto reiteradamente el Tribunal Supremo, la custodia compartida se acordará judicialmente una vez valorados los criterios los elementos personales y materiales concurrentes, debiéndose siempre hacer efectiva la protección del interés del menor de la mejor manera posible, no el interés de los progenitores, ni como un sistema de premio o castigo al cónyuge por su actitud en el ejercicio de la guarda (STS 1a 11 marzo de 2010, STS $1^{\text {a }}$ de 1 de octubre de 2010). Es clara la STS $1^{\text {a }}$ de 11 de marzo de 2010 cuando dice que: "(...) la guarda compartida no consiste en "un premio o un castigo" al progenitor que mejor se haya comportado durante la crisis matrimonial, sino en una decisión, ciertamente compleja, en la que se deben tener en cuenta los criterios abiertos ya señalados que determinan lo que hay que tener en cuenta a la hora de determinar el interés del menor..." Esta determinación -se dice en la STS 1a de 1 de octubre de 2010- debe basarse en razones objetivas. Es decir, en esta materia deben ser superados los viejos prejuicios fundados en el "deber ser de las cosas", o el orden natural, y ceñirnos a los principios constitucionales en tanto desarrollo de la personalidad, igualdad y no discriminación de los padres, así como de protección y libre desarrollo de la personalidad del menor; entendiendo la justificación de la familia en tanto sirva de cauce para el pleno desarrollo de sus miembros, incumbiendo muy especialmente a los padres este deber.

Por demás, como ya sabemos, entiende el Alto Tribunal que "hay que precisar que todo régimen de custodia tiene sus ventajas y sus inconvenientes" aunque bien es verdad que la redacción del Art. 92 C.C no permite concluir que se trate de una medida excepcional sino que, al contrario, debería considerarse la más normal, porque permite que sea efectivo el derecho que los hijos tienen a relacionarse con ambos progenitores, aún en situaciones de crisis, siempre que ello sea posible y en tanto en cuanto lo sea, insistiéndose también en que ningún sistema de guarda presenta primacía, ni preferencia, ni excepcionalidad (SSTS $1^{\text {a }}$ de 7 y 22 de julio de 2011, STS $1^{\text {a }}$ de 10 de enero de 2012 ).

Y corresponde al Juez la valoración de los elementos fácticos concurrentes en cada caso para concluir si ha de aplicarse o no la custodia compartida en cada caso concreto; así se expresa la STS 1ํㅡ de 29 de abril de 2013:

Es al Juez al que, en el marco de la controversia existente entre los progenitores, corresponde valorar si debe o no adoptarse tal medida considerando cuál sea la situación más beneficiosa para el niño; y si bien se confiere a los progenitores la facultad de autorregular tal medida y el Ministerio Fiscal tiene el deber de velar por la protección de los menores en este tipo de procesos, sólo a aquel le corresponde la facultad de resolver el conflicto que se le plantea, pues exclusivamente él tiene encomendada constitucionalmente la función jurisdiccional, obligando a los progenitores a ejercerla conjuntamente sólo cuando quede demostrado que es beneficiosa para el menor. Lo dicho no es más que el corolario lógico de que la continuidad del cumplimiento de los deberes de los padres hacia sus hijos, con el consiguiente mantenimiento de la potestad conjunta, resulta sin duda la mejor solución para el menor por cuanto le permite seguir relacionándose del modo más razonable con cada uno de sus progenitores, siempre que ello no sea perjudicial para el hijo, desde la idea de que no se trata de una medida excepcional, sino que al contrario, debe considerarse la más normal, porque permite que sea efectivo el derecho que los hijos tienen a mantener dicha relación.

Dicho de otro modo, para el Alto Tribunal la custodia compartida no es una medida excepcional pero, a priori, es la mejor solución para un menor porque le permite relacionarse con sus padres del modo más razonable y ello será así, siempre que no sea perjudicial para el hijo, valorando el conjunto de circunstancias fácticas concurrentes; valoración que corresponde al Juez.

Debe remarcarse la idea de que, por encima de todos los parámetros, condiciones y factores expuestos no basta con exponer teorías 
jurídicas y psicológicas, como señala la citada SAP Barcelona $12^{\mathrm{a}}$ de 27 de febrero de 2013, lo importante es asegurar que para cada caso concreto la opción que se adopte sea la mejor para los hijos menores. Se ha de tener en cuenta que la custodia compartida no puede ser concebida como un premio o una recompensa para uno de los progenitores o una reprobación para el otro. La decisión ha de ser adoptada sobre la base del interés del menor, interés que como expone la STS $1^{\text {a }}$ de 29 de noviembre de 2013 “...ni el artículo 92 del Código Civil ni el artículo 9 de la Ley Orgánica 1/1996, de 15 de enero, de Protección Jurídica del Menor , definen ni determinan..."

Hemos visto hasta aquí los principios, criterios y factores para la atribución de guarda y custodia, en general y, específicamente, de la custodia compartida así como las condiciones que facilitan la instauración de este modelo. A la vista de lo anterior ¿cómo están conjugando los Jueces y Tribunales todos estos parámetros?, ¿cuál es la práctica judicial sobre la custodia compartida?

Examinaremos seguidamente, mediante el examen de la Jurisprudencia más reciente los factores que valoran los jueces para atribuir la custodia compartida.

\subsection{La relación de los progenitores entre sí y con los hijos: La actitud de los progenitores tras la ruptura, estilos educativos y otras circunstancias relativas a la estabilidad emocional del menor}

Dispone el Art. 92.6 C.C que para acordar cualquier régimen de custodia el juez tendrá en cuenta, entre otras cuestiones, "la relación que los padres mantengan entre sí". El precepto no señala ninguna pauta de interpretación, quedando, por tanto, en manos del Juez la decisión sobre qué tipo de relación debe existir entre los progenitores para que pueda acordarse la custodia compartida.

En este sentido, judicialmente se valora que exista una similitud en los modelos educativos, esto es, la capacidad de los padres para mantener un modelo educativo común, de manera que el tránsito de un hogar a otro no sea traumático sino imperceptible para los menores quienes, de otro modo, perderán los referentes y estabilidad emocional. Como señala la Jurisprudencia, la diferencia de estilos educativos de ambas partes (habitualmente, uno más permisivo y otro más exigente) si bien no puede considerarse perjudicial para el menor, quien debe adaptarse a la realidad que le ha tocado vivir, no se considera idóneo para acordar la custodia compartida, pues ello implicaría tensiones y desacuerdos constantes entre las partes que serían de difícil concierto entre ellos, derivando la situación en una desarmonía constante para el menor (SAP Valencia 10 ${ }^{\text {a }}$ de 7 de junio de2005, SAP Barcelona 12a de 26 de octubre de 2006, SAP Madrid 22a de 16 de octubre de 2007). A modo de ejemplo, en la SAP Bizkaia $4^{a}$ de 18 de mayo de 2011 se desestima una demanda de modificación de medidas pues, si bien ambos progenitores son adecuados para el ejercicio de la guarda y custodia, no es factible la custodia compartida al existir disparidad de criterios en cuanto a los puntos clave de la educación de las menores, dado que estas precisan de unos límites más estrictos de los que el padre ofrece. Especialmente ilustrativa en la cuestión analizada resulta la SAP Valencia $10^{a}$ de 17 de diciembre de 2012 cuando, con respecto de las discrepancias en el estilo educativo, estima que "no pueden minimizarse sus consecuencias, pues estas discrepancias pueden llegar a entorpecer un desarrollo psicosocial adecuado por parte de los menores"; en el caso de autos existían indicadores de una posible dificultad por parte del padre para hacer cumplir normas y poner límites a los me $n$ nores, así como para ayudarles a que aprendan su importancia, aspecto que puede afectar negativamente a su desarrollo psicosocial, motivos que llevan a la Sala a descartar la custodia compartida. Finalmente, cabe destacar la SAP Álava 1a de 7 de junio de 2013 cuando indica que:

La discrepancia sobre los criterios o pautas educativas y la deficiente coor $\neg$ dinación en el ejercicio de la patria potestad son circunstancias desfavorables al interés de los menores, por lo que los progenitores deben dirigir sus esfuer $\neg$ zos a superar esa situación, cualquiera que sea el régimen de custodia. En este caso esas circunstancias representan un impedimento para establecer la custodia compartida. Las partes deberán proceder activamente a superar tales dificultaาdes y sentar las bases de un régimen de custodia compartida efectivo en un plazo razonable. 
No obstante, las divergencias en los modelos educativos pueden no llegar a ser determinantes para excluir la custodia compartida. En este sentido, establece la SAP Murcia $5 \underline{\text { a de }} \mathbf{2 6}$ de junio de 2012 que las diferencias de estilos educativos no debe afectar en modo alguno a la custodia compartida, siempre que ambos tengan capacidad para mantener los roles del otro progenitor frente a los hijos, pese a los problemas de comunicación que puedan tener en sus relaciones personales. Esto demuestra que, afortunadamente, ambos hacen prevalecer el interés de los menores sobre sus propios intereses o sentimientos personales.

Lo expuesto en relación a los modelos educativos nos lleva a análisis del factor -genérico del anterior- relativo a la "relación que los progenitores mantengan entre sí". En principio, la necesidad de que los progenitores logren separar sus diferencias personales y actúen con relación y frente a los hijos con un cierto grado de consenso educacional, no es sólo un presupuesto legal sino que será la base para el éxito de esta fórmula de custodia. En esta línea, la Instrucción de la Fiscalía General del Estado 1/2006 de 7 de marzo ya señalaba que: "En todo caso, ha de partirse que para admitir la guarda y custodia compartida debe valorarse especialmente la existencia una buena relación entre los progenitores que les permita postergar su desencuentro personal en aras al beneficio del hijo común (vid. SAP Las Palmas $n^{\circ}$ 327/2004, de 15 de abril, SAP Barcelona $n^{-}$ 140/2004, de 3 de marzo). ...."

Tradicionalmente, una mala relación personal entre los progenitores ha venido siendo la causa alegada con más frecuencia por nuestros Tribunales para la denegación del régimen de custodia compartida. Las evidencias de que el proceso de ruptura se haya desarrollado con la presencia de conflictos, tensiones, desavenencias, etc., entre los progenitores dan lugar a desestimar frecuentemente la custodia compartida como régimen de guarda. Los ejemplos en este sentido en la Jurisprudencia menor son numerosos; es clara esta doctrina en la SAP Madrid 22 ${ }^{\text {a }}$ de 21 de julio de 2009 según la cual "No se acuerda la custodia compartida porque los padres priorizan el mantener el conflicto e interponer continuamente denuncias entre ellos que en buscar una solución para que la situación educativa, sanitaria, relacional, emocional y psicológica de su hijo sea más favorable y positiva". También resulta ilustrativa la SAP Sevilla $2^{\text {a }}$ de 1 de abril de 2009 que no concede la custodia compartida por la excesiva judicialización de las relaciones entre los progenitores y el elevado grado de conflictividad existente entre ellos. Igualmente la SAP Bizkaia $4^{\text {a }}$ de 31 de octubre de 2008, indica que " $L a$ relación de los progenitores ha sido, y parece que es, muy conflictiva con total incomunicación, por lo que bajo el prisma del interés del menor no procede conceder la custodia compartida"; la SAP Asturias $4^{\underline{a}}$ de 3 de julio de 2008 que señala:

El informe emitido por el perito judicial sigue optando por la guarda materna mientras que la documental, expresiva de continuas denuncias entre los litigantes, revela principalmente una situación de continuo enfrentamiento que no parece la más adecuada para el sistema que se pretende establecer de custodia compartida que precisa de una relación pacífica, serena y fluida entre los progenitores que permita que se sucedan los continuos turnos en la custodia sin alteraciones relevantes que perjudiquen la necesaria estabilidad del niño.

Por su parte la SAP Almería 2a de 27 de diciembre de 2012 reseñan que:

Las relaciones entre los padres no parecen las más adecuadas para establecer la custodia compartida habida cuenta de las serias desavenencias que presentan. No en vano consta que durante el proceso de ruptura se vieron envueltos en un procedimiento ante el Juzgado de Violencia y que vivieron un episodio de tensión considerable como consecuencia de la decisión de cambio de centro escolar de los menores (...).

En parecidos términos se expresan resoluciones de fechas anteriores como las SAP León $3^{\circ}$ de 13 de octubre de 2006, SAP Zaragoza $4^{\text {a }}$ de 14 de noviembre de 2006, SAP Madrid 22a de 2 de marzo de 2007, SAP Madrid 22a de 9 de marzo de 2007, SAP Bizkaia 4⿳亠丷a de 20 de marzo de 2007, SAP Barcelona 12 16 de octubre de 2007.

Dentro de la Jurisprudencia mayor, igualmente, la STS 1a de 22 de julio de 2011 confirmó la sentencia de la Audiencia Provincial que no acordó la custodia compartida con base en las malas relaciones existentes entre los padres. Y en la STS 1 $\mathbf{1}^{\mathbf{a}}$ de 9 de marzo de 2012 no se accede a la custodia compartida al declarar probado en la sentencia recurrida que las relaciones entre los progenitores 
era conflictiva, pues solo se comunicaban vía SMS. Y en la más reciente STS $\mathbf{1}^{\mathrm{a}}$ de $\mathbf{3 0}$ de octubre de 2014 se confirma como inadecuada la custodia compartida al constatarse la existencia de llamadas telefónicas, por parte del padre, que entendía el Juzgador a quo como agresivas, con base en lo que había deducido de testimonio para el Juzgado de Violencia contra la Mujer.

Ahora bien, de un tiempo a esta parte, muchas resoluciones judiciales han venido a relativizar, ponderando en su justa medida el alcance $y$ virtualidad de la constatación de una mala relación personal entre los progenitores. Esto debido a que junto a parejas con una relación personal beligerante existen otras situaciones distintas en las que las relaciones de los progenitores, quienes cesaron en la convivencia, no son ni violentas, ni gravemente enfrentadas, ni belicosas; en ocasiones los progenitores sólo hablarán de lo imprescindible, en otras habrá una comunicación fluida e, incluso, pueden existir supuestos en los que no exista la más mínima comunicación entre ellos pero tampoco se presenten denuncias, ni especial conflictividad. En todos estos casos ¿no resulta posible acordarse judicialmente la custodia compartida? Para la Jurisprudencia, en el ámbito del TSJ de Cataluña, resulta doctrina consolidada que cualquier grado de conflictividad no puede excluir a priori el ejercicio conjunto, sin procurar su implantación cuando resulta beneficiosa para los hijos, aún cuando sea imponiendo en determinados casos la mediación o terapias educativas. En las SSTSJ Cataluña, Sala Civil-Penal, de 8 de marzo de 2010 y 31 de julio de 2008 se viene a indicar al respecto que la guarda y custodia compartida no es adecuada en supuestos de conflictividad extrema entre los progenitores, especialmente siempre que existan malos tratos, sin que ello signifique, sin embargo, que deba desecharse frente a cualquier grado de conflictividad y que no deba procurarse su implantación cuando resulta beneficiosa para los menores:

(...) no es adecuada en supuestos de conflictividad extrema entre los progenitores, especialmente siempre que existan malos tratos, a causa de la continua exposición del niño al enfrentamiento, en cuyo caso la ponderación de los intereses en juego, en especial los del niño, debe ser extremadamente cuidadosa y subordinada a la protección jurídica de la persona y de los derechos de personalidad de los menores afectados; sin que ello signifique, sin embargo, que deba desecharse frente a cualquier grado de conflictividad y que no deba procurarse su implantación cuando resulta beneficiosa para los menores, aunque sea imponiendo en determinados casos la mediación familiar o terapias educativas(...).

A tenor de esta línea jurisprudencial, resultaría lógico entender que la custodia compartida no resultará adecuada ni conveniente "en supuestos de enfrentamiento y conflictividad extrema entre los progenitores" y ello ocurre especialmente siempre que existan malos tratos, a causa de la continua exposición del niño al enfrentamiento, en cuyo caso la ponderación de intereses en juego, en especial los del niño, debe ser extremadamente cuidadosa y subordinada a la protección jurídica de la persona y de los derechos de personalidad de los menores afectados. Siguiendo esta doctrina, en la STSJ de Cataluña, Sala Civil -Penal, de 25 de junio de 2009, se denegó el ejercicio de la guarda conjunta, manteniéndose la monoparental, por no resultar lógica ni arbitraria en atención al status familiar, tras apreciar la importante conflictividad, con denuncias de malos tratos, incumplimientos del régimen de guarda y visitas, y la necesidad de intervención de un pariente durante unos días en el cuidado de los menores, con la finalidad de no descompensarlos y procurar estabilizarlos en su nuevo entorno.

Pero fuera de estas situaciones de violencia o grave conflictividad entre los progenitores quienes, al perjudicar el interés del menor, deben sin duda impedir la instauración judicial del sistema de custodia compartida, cabe preguntarse: ¿una mala relación personal entre los progenitores impide la custodia compartida?, ¿no resulta posible que, en ocasiones, aunque exista una mala o pésima relación personal entre los progenitores, exista también una excelente relación parental que conviene fomentar?, ¿qué tipo de relación debe existir entre los progenitores que no impida la custodia compartida?

De inicio parece claro que, evidentemente, no puede exigirse una relación perfecta y ejemplar entre los progenitores porque resulta lógico e inevitable que la relación personal entre ellos se encuentre deteriorada; al fin y al cabo no podemos olvidar que entre ambos ha ocurrido una ruptura como pareja. Así se expresan diversas 
resoluciones de la Jurisprudencia menor. La SAP Baleares $4^{\mathrm{a}}$ de 14 de julio de 2009 nos viene a señalar unas pautas razonables para valorar la relación entre los progenitores: "En dicho punto, se considera conveniente referir que, con carácter general, si bien la relación que mantienen los padres ha de valorarse, conforme se establece en el artículo 92.6 del Código Civil, para acordar la medida de guarda y custodia compartida, tampoco puede el Tribunal exigir al respecto que la relación sea de todo punto ejemplar". Por eso no faltan resoluciones de la Jurisprudencia menor que establecen la custodia compartida a pesar de la desavenencia y conflictividad entre los progenitores; como en la SAP Girona 1a de 27 de julio de 2012 que insiste en la idea de que únicamente en casos de grave conflictividad y enfrentamiento entre ambos progenitores se desaconseja el sistema de guarda y custodia compartida, teniendo que en el caso enjuiciado, simplemente se constata "la conflictividad propia de una separación matrimonial que deberá irse solventándose en el futuro". Por tanto no ha de constatarse una relación violenta o gravemente conflictiva pero a tenor de esta línea jurisprudencial tampoco puede exigirse una relación personal ideal, perfecta o ejemplar e, incluso, cabe que no deba desecharse frente a cualquier grado de conflictividad cuando resulta beneficiosa para los menores.

En el mismo sentido, en la Jurisprudencia mayor, la STS $1 \underline{\text { a }}$ de 16 de octubre de 2014 casa una resolución que niega la custodia compartida con estas palabras

(...) hemos de declarar que en la sentencia recurrida se infringe la doctrina jurisprudencial, dado que la tensa situación que concurre en los cónyuges no consta que sea de un nivel superior al propio de la situación de una crisis conyugal. Por otro lado se acredita la favorable disposición de los menores, la gran aptitud de ambos padres para ostentar la custodia y que se abstienen de predisponer negativamente a los hijos, todo lo cual motiva la admisión del sistema de custodia compartida, como medida más favorable en interés de los menores.

Esta línea de pensamiento ha tenido su refrendo por parte del Tribunal Supremo; en sus consideraciones obiter dicta, las SSTS $1^{\text {a }}$ de 8 de octubre de 2009, 7 y 21 de julio de 2011 reseñan que la medida de custodia compartida supondrá una convivencia forzosamente más compleja que la que se lleva a cabo cuando los progenitores conviven. Más claramente, en la STS 1 a de 9 de marzo de 2012 -que reitera su doctrina jurisprudencial ya contenida en la STS $\mathbf{1}^{\mathbf{a}}$ de 22 de julio de 2011-, a pesar de confirmarse las resoluciones de instancia denegando la custodia compartida con base en las malas relaciones personales entre los progenitores, se señala con claridad expositiva, razonando así la desestimación de los recursos de casación, que “(...) las relaciones entre los cónyuges por sí solas no son relevantes ni irrelevantes para determinar la guarda y custodia compartida. Solo se convierten en relevantes cuando afecten, perjudicándolo, el interés del menor". Esta idea es reiterada posteriormente en la STS $1 \underline{a}$ de 29 de noviembre de 2013 , la cual se hace hincapié en que, en ocasiones, unas malas relaciones pueden perjudicar el interés del menor

(...) como sucede en supuestos de conflictividad extrema entre los progenitores, especialmente siempre que existan malos tratos, a causa de la continua exposición del niño al enfrentamiento" añadiendo que " se prima el interés del menor y este interés, que ni el artículo 92 del Código Civil ni el artículo 9 de la Ley Orgánica 1/1996, de 15 de enero, de Protección Jurídica del Menor, definen ni determinan, exige sin duda un compromiso mayor y una colaboración de sus progenitores tendente a que este tipo de situaciones se resuelvan en un marco de normalidad familiar que saque de la rutina una relación simplemente protocolaria del padre no custodio con sus hijos que, sin la expresa colaboración del otro, termine por desincentivarla tanto desde la relación del no custodio con sus hijos, como de estos con aquel.

En esta resolución se abunda también en la necesidad de que los Tribunales de instancia señalen y precisen razonadamente los motivos o circunstancias concretas que desaconsejan, por perjudicar al menor, la instauración de cualquier tipo de guarda, incluida la compartida. Como colofón, la STS 1a de 30 de octubre de 2014 ha venido a poner de manifiesto que

Esta Sala debe declarar que la custodia compartida conlleva como premisa la necesidad de que entre los padres exista una relación de mutuo respeto que permita la adopción actitudes y conductas que beneficien al menor, que no perturben su desarrollo emocional y que pese a la ruptura 
afectiva de los progenitores se mantenga un marco familiar de referencia que sustente un crecimiento armónico de su personalidad.

Por tanto, y en síntesis, parece que la cuestión de si una (mala) relación entre los progenitores entre sí puede impedir la adopción judicial de un sistema de custodia compartida debe reconducirse, en definitiva, a constatar si esa (mala) relación perjudica o no al menor. Ahora bien ¿cómo se puede constatar judicialmente ese perjuicio? La respuesta nos la brindan alguna resoluciones de la Jurisprudencia menor: El factor de la mala relación personal entre los progenitores solo debe valorarse negativamente a aspectos de la custodia compartida en la medida en que ambos no sean, o no hayan sido, capaces de adoptar decisiones relativas a los hijos menores, manteniéndolos apartados, preservados o aislados del conflicto entre ellos existente. De manera que, si así sucede, no resulta conveniente la adopción del sistema de custodia compartida (SAP Barcelona $12^{\mathrm{a}}$ de 18 de septiembre de 2014). Y, a contrario, si los hijos han sido aislados y separados del conflicto personal entre sus padres, no afectándoles significativamente, es posible instaurarse este sistema de guarda (SAP Barcelona 12a de 19 de diciembre de 2012, SAP Asturias 5a de 11 de diciembre de 2014). En consecuencia, parece claro en virtud de esta línea de pensamiento de la Jurisprudencia menor y mayor, que a pesar de que pueda ser un hecho evidente la mala relación entre los progenitores ello no debe implicar, sin más, que deba rechazarse el sistema de custodia compartida cuando su implantación resulta más beneficiosa para los menores, pues cualquier grado de conflictividad no puede constituir un óbice para ello, máxime teniendo en cuenta que, ante todo, debe primar el interés superior de los hijos. En síntesis, parece razonable que la mención que se hace en el Art. 92 C.C a que se valore "la relación que los padres mantengan entre sí" debería interpretarse siguiendo las pautas que se contienen en las anteriores sentencias, dado que una interpretación restrictiva tendría la consecuencia de erigir a este requisito en un obstáculo insalvable para la concesión de la custodia compartida y podríamos encontrarnos con supuestos en los que podrían tensarse las relaciones, por uno de los progenitores, para aparentar una situación incompatible con la custodia compartida.
Centrada la cuestión en la valoración de las relaciones entre los progenitores y de los estilos educativos de ambos, a efectos de la atribución de la custodia compartida, como se apunta desde la Psicología, se trataría de mantener el lazo familiar aunque el lazo conyugal se haya roto; eso no quiere decir que los progenitores se tengan que llevar a las mil maravillas; después de la ruptura eso suele ser bastante raro y podemos contentarnos con un mínimo de buen entendimiento en lo que respecta a las decisiones básicas educacionales relacionadas con la educación del hijo ${ }^{18}$. Debe comprobarse, por tanto, una capacidad mínima de entendimiento, no obstante la ruptura personal, de ambos progenitores con respecto a los hijos. Como explican los psicólogos ${ }^{19}$, aunque es indudable que sería muy conveniente que entre ambos progenitores existiera una buena relación en la que el mutuo respeto y la colaboración fueran pilares básicos, lo cierto es que habitualmente esto no siempre va a ser así, sino todo lo contrario, que tras la ruptura los progenitores no lleguen a entenderse pues, a fin de cuentas, esa es la razón por la que han llegado a la ruptura personal. Sin embargo, aún cuando entre ambos existan esas malas relaciones, mientras mantengan adecuada relación en cuanto a sus hijos, implicándose en su crianza, la custodia compartida puede funcionar.

En esta línea, un factor indicativo para valorar la relación entre los progenitores puede venir configurado por el desarrollo, ejecución y cumplimiento de un previo régimen de visitas que, antes de la petición de custodia compartida, haya podido tener lugar, lo que se puede estimar, claramente, como un indicio de la falta de acuerdo en común de los progenitores para solventar sus diferencias personales, en un marco en el que el hijo no quede aún más perjudicado. (SAP Zaragoza 4⿳a de 14 de noviembre de 2006); un cumplimiento poco riguroso del régimen de visitas establecido, en ocasiones sin causa justificada, puede valorarse negativamente para denegar la custodia compartida (SAP Barcelona 12 ${ }^{\mathrm{a}}$ de 23 de enero de 2015); de igual manera puede razonarse respecto al grado de cumplimiento de un previo deber de pago alimentos: un incumplimiento reiterado supone un grave impedimento para poder acceder a la petición de guarda y custodia compartida (SAP Baleares $4^{\mathbf{a}}$ de 6 de abril de 2011).

18. POUSSIN, Gerard., LAMY, Anne., op. cit., p. 56

19. AGUILAR, José Manuel. Con mamá y con papá, Editorial Almuzara, 2006, p. 85. 
Por otra parte, parece razonable pensar que la mención que se hace en el Art. 92 C.C a que se valore "la relación que los padres mantengan entre sí, debería interpretarse siguiendo las pautas que se contienen en las anteriores sentencias, puesto que una interpretación restrictiva tendría la consecuencia de erigir a este requisito en un obstáculo insalvable para la concesión de la custodia compartida y podríamos encontrarnos con supuestos en los que bastase que uno de los progenitores tensase las relaciones personales, aparentando una situación de incomunicación, para que lograse la denegación judicial de la custodia compartida. Desde la Psicología se pone el énfasis en que, con tal solución, se pone el énfasis en que otra solución solo llevaría a otorgar una especie de "derecho de veto" a uno de los progenitores, al que potencia y fomenta el conflicto, pone trabas y mina los acuerdos, buscando hacer fracasar el sistema. Y -se dice- esto sería un punto a favor del progenitor beligerante cuando, por el contrario, a quien se debería "premiar" sería al progenitor "conciliador", aquel quien facilita los contactos entre el niño y su ex-pareja ${ }^{20}$. En la Jurisprudencia sigue este mismo razonamiento la SAP Valladolid $1^{\text {a }}$ de 22 de diciembre de 2011, cuando explica que la conflictividad solo puede servir de freno a la custodia compartida en caso de que sea extrema, sin que pueda desecharse este modelo de custodia frente a cualquier grado de conflictividad, pues bastaría que cualquiera de los progenitores se encastillase en evitar cualquier relación o comunicación con el otro, para luego utilizar tal circunstancia como pretexto de oposición a la guarda conjunta. Con más claridad y en este sentido, la SAP Pontevedra $1^{\text {a }}$ de 24 de septiembre de 2014, recuerda que no puede denegarse la custodia compartida solo con base en la mala relación de los cónyuges, sin que resulte probado que perjudica el interés del menor o que se trata de una circunstancia superable, de modo que

(...) resultando que la conflictividad aludida es principalmente fomentada por la madre que no llega a probar en ningún momento las razones serias para la desconfianza en la custodia de su hija por parte del padre, aboga por dejar de lado falsos paternalismos que llevados a extremos injustificados repercuten en la familia, separando a la hija del trato con su padre

20. POUSSIN, Gerard; LAMY, Anne. op. cit. p. 32

21. AGUILAR, José Manuel. Con mamá..., op. cit. , p. 85. sin motivo alguno y sometiéndola a una tensión perjudicial en las expectativas de su formación, cuando lo más beneficioso es acercarse a un modelo de convivencia próximo al existente antes de la ruptura.

En síntesis, parece que resulta conveniente analizar cada familia, valorando cada caso concreto; la relación existente entre los progenitores es un factor relevante e importante -muy importante- pero no debe ser el único para determinar la conveniencia o no de una guarda y custodia compartida. Desde luego, parece claro que la conflictividad entre los progenitores debe ser una variable determinante en aquellos casos en que perjudique o ponga en riesgo el bienestar del menor, lo que sin duda sucederá cuando la relación es violenta. También es cierto que existe una mayor frecuencia de casos en los que una relación conflictiva, sin ser violenta pero con falta de comunicación y acuerdos en relación a los hijos, se asocia con un aumento del malestar en los menores. Ahora bien, debe abrirse la posibilidad de instaurar un sistema de custodia compartida a pesar de dichas dificultades de relación personal, preservando siempre el bienestar emocional de los menores, valorando bien la posibilidad de que dichas dificultades entre los progenitores se lleguen a cronificar o, bien, que simplemente sean las propias de la reciente ruptura personal. Yendo más allá, los psicólogos ${ }^{21}$ indican que la instauración de un sistema de custodia compartida coadyuva a mejorar una previa mala relación y disminuir el conflicto entre los progenitores; ante el reparto igualitario y equitativo de tiempos, derecho y responsabilidad, el nivel de cumplimiento de los acuerdos y convenios aumentaría; si un progenitor tiene las mismas posibilidades de actuar y hacer que el otro, tiende a no actuar del modo que no le gustaría recibir.

\subsection{Circunstancias relativas a la estabilidad física del menor}

\subsubsection{La ubicación de domicilios de los progenitores. La proximidad geográfica entre los domicilios de los progenitores: El trasiego como causa de desestabilidad física y “deslocalización" del menor}

Naturalmente partimos de la base de que ambos progenitores dispongan de una vivienda, en condiciones dignas y adecuadas, donde poder alojar a los hijos en los tiempos alternos en que 
pudieran corresponderle su cuidado (incluida la pernocta) pues, caso contrario, si uno de los progenitores carece de ella, o no tiene una condiciones adecuada, la custodia compartida es inviable (SAP Barcelona $12^{\underline{a}}$ de 9 de enero de 2013).

Muy habitualmente, en algunas resoluciones de la Jurisprudencia, se pone de manifiesto que la custodia compartida, en puridad jurídica es un contrasentido en sí misma pues redundaría en perjuicio del menor por su continuo peregrinaje de un lugar a otro; o, de quedarse la menor en el domicilio familiar, por el cambio continuo de costumbre, según accedieran al domicilio familiar el padre o la madre, y su repercusión en las relaciones del menor con su familia, amigos y compañeros de clase, estudios, etc., así como por la pérdida de una referencia estabilizadora (SAP Barcelona 12a de 29 se septiembre de 2006, SAP Madrid 24a ${ }^{a}$ de 25 de octubre de 2006, SAP Córdoba $2^{a}$ de 1 de junio de 2009, SAP Madrid 22a de 16 de julio de 2010). Se señala que la falta de esta referencia estabilizadora o "deslocalización", puede perjudicar al menor e influir:

- En el rendimiento escolar del menor: Olvidos en su día de material escolar, aunque también disponga de todo lo necesario en ambas viviendas o que, aún poseyendo los libros de curso en las dos, se dé la circunstancia de que en los que tenga en la de alguno de los progenitores falte la anotación pertinente que el profesor haya recomendado o llevado a cabo en determinado momento, sin que el hijo la haya anotado en el otro y no recuerde los términos en que se realizó.

- En las relaciones del menor con sus compañeros: No tanto en el colegio, cuanto en la necesaria relación social fuera del mismo ya que la comunicación, el contacto, puede resultar afectado por el trasiego continuo entre viviendas que, llegado un momento, dada la edad de quienes con el hijo se relacionen, pueda generar dudar, si no ignorar, en cuál de las dos viviendas pueden contactar con ellos; sin que obste a ello el sistema de comunicación telefónica, que puede llevar a quien no lo localice en la vivienda, en la cree que habita, a desistir de acercarse a la otra, teniendo en cuenta la mayor o menor distancia que pueda existir entre ellas. Lo anterior sin tener en cuenta el supuesto de enfermedad del hijo durante tan corta estancia en la vivienda de uno de los progenitores y su incidencia en la vuelta a la del otro, con la también consiguiente litigiosidad entre los mismos que ello pueda ocasionar.

Sin embargo, cabe preguntarse si los cambios de domicilio siempre y necesariamente han de ser causa de desestabilización en el menor.

En principio, como señalan los psicólogos ${ }^{22}$, es bien cierto que, aunque los progenitores cambien de vida, el hijo debe mantener los mismos o parecidos hábitos de antes. Más aun en el caso de adolescentes, para quienes el mantenimiento de sus referencias suele ser "condictio sine qua non" para que se adhieren al sistema de guarda compartida. Por consiguiente, el hijo en custodia compartida debe continuar estudiando en el mismo colegio o instituto, debe conservar sus amistades o realizar las mismas actividades de ocio de antes, en definitiva, mantener el referente estabilizador del entorno habitual del menor: Si este entorno habitual no se mantiene mínimamente, procedería la denegación de custodia compartida propuesta porque, en tales casos, en efecto, puede llegar a entenderse que perjudica el interés superior del menor.

Por ello, inicialmente la proximidad física de los domicilios de los progenitores garantiza unas mínimas referencias vitales, así como el mantenimiento del entorno habitual del menor. ¿Supone eso que los progenitores deben de vivir en la misma calle? Señalan los psicólogos ${ }^{23}$ que quizás eso sea exagerado, aunque sí que es bastante práctico que los progenitores vivan en barrios cercanos pues es una buena manera de que los niños y adolescentes mantengan unas mismas referencias vitales (la plaza, el parque, la piscina, los amigos...) y los adultos no pierdan tiempo en transportes.

Lo lógico es que la proximidad física de los domicilios implique el mantenimiento de colegio, amistades del menor, médico, actividades extraescolares... Incluso, aunque los domicilios estén en la misma ciudad, aunque no cercanos, podría ser adecuada la custodia compartida alternativa, que, sí en cambio parece desaconsejable en caso de residir en ciudades distintas (cambio de colegio,

22. POUSSIN, Gerard; LAMY, Anne. op. cit. , p. 57.

23. Ibíd., p. 55 
de entorno...). Por ello, la lejanía derivada de unas diferentes poblaciones de residencia de los progenitores como motivo de inestabilidad del menor hace inviable la custodia compartida en diversas resoluciones jurisprudenciales (SAP Barcelona 18 ${ }^{\mathrm{a}}$ de 4 de octubre de 2006, SAP Madrid 22a de 1 de diciembre de 2006, SAP Barcelona 18 ${ }^{a}$ de 14 de diciembre de 2006, SAP Alicante 4a de 22 de febrero de 2007, SAP Gipuzkoa 2a de 18 de junio de 2007, SAP León $2^{a}$ de 8 de febrero de 2013). A modo de ejemplo, la SAP Barcelona 12 ${ }^{\underline{a}}$ de 5 de octubre de 2011 considera que 29,2 Kms. de distancia (Sabadell - Barcelona) son insalvables para la custodia compartida pretendida por el padre. Ello, no obstante que, paradójicamente, fuera del proceso contencioso, en muchos Convenios Reguladores, no son infrecuentes acuerdos entre los progenitores de custodia compartida en los que las de residencias de ambos se encuentran en poblaciones distantes, incluso 20 ó $30 \mathrm{kms}$. entre sí (SAP Barcelona 12 ${ }^{\underline{a}}$ de 13 de enero de 2012).

Esta solución desestimatoria de la custodia compartida se hace mucho más patente en el caso de la combinación hijo de muy corta edad traslado a gran distancia, con domicilios en diferentes localidades; la necesidad de un contacto frecuente de corta duración, combinada con un traslado a una gran distancia entre domicilios, de inicio, parece que solo puede perjudicar al menor (SAP Granada 5a de 4 de febrero de 2011).

En este sentido, y sin perjuicio de lo expuesto, nuestro alto Tribunal, en recientes resoluciones, matiza que lo importante no es la distancia física y material entre los domicilios de los progenitores sino valorar y motivar judicialmente si dicha circunstancia garantiza o no, y de qué manera, la estabilidad y el interés superior del menor. En la reiteradamente citada STS $1^{\mathbf{a}}$ de 8 de octubre de 2009 se señala que incurre en falta de motivación la sentencia de apelación que denegó la custodia compartida, únicamente sobre la base de la no permanencia de los menores en un domicilio estable, cuando es consustancial a la guarda y custodia compartida que los hijos vivan con sus padres en domicilios cambiantes. En la STS 1a de 11 de marzo de 2010 (reiterada en las SSTS 1a de 7 y 21 de julio de 2011) se entiende que la "deslocalización" de los niños alegada por la Audiencia Provincial no debe ser un motivo en sí mismo para negar el establecimiento de la custodia compartida. Se rechaza el criterio de la "deslocalización" de los niños para no aplicar la custodia compartida, pues se entiende que los cambios de domicilio son una consecuencia inherente a este tipo de guarda. Por demás, se insiste en que no cabe un rechazo en abstracto y que debe explicarse cómo la distancia entre domicilios perjudica, concretamente, el interés superior del menor en el caso, debiendo ser adecuadamente motivada la decisión por el juzgador.

Por demás, algunos psicólogos entienden que lo que debe valorarse judicialmente es si la mayor o menor proximidad de los domicilios de los progenitores garantiza, efectivamente, la estabilidad del menor, no únicamente en el sentido físico o material. En efecto, no faltan opiniones entre los psicólogos ${ }^{24}$ que habitualmente entienden la estabilidad del menor más como el mantenimiento de los espacios materiales, el entorno físico del menor, y menos como la continuidad de las relaciones afectivas y del entorno emocional del menor, olvidando por completo los concluyentes resultados que la investigación psicológica ha expuesto sobre la mayor importancia de este último aspecto. Se añade, además, que si nos fijamos en la rutina diaria de cualquier familia no separada, podremos descubrir que los menores están adaptándose continuamente a los cambios que la vida familiar implica, cambios que se aceptan sin que impliquen desajustes ni desestabilización en los menores. Ello es más frecuente en las familias en las que ambos progenitores trabajan $y$ donde se hace necesario contar con el apoyo externo de cuidadores (familia extensa o personas contratadas), guarderías extraescolares, comedores escolares, etc.

En esta línea, precisamente, la STS 1a de $\mathbf{1 0}$ de marzo de 2010, lejos de partir de la premisa de que lo mejor para el menor es mantener su estabilidad geográfica, bajo la custodia de la madre, opta por afirmar que la cláusula abierta del interés superior del menor exige acordar esta medida siempre en interés del menor, es decir, que tiene preferencia la estabilidad emocional y relacional del menor con sus dos progenitores de forma paritaria, antes que separarlo de uno de ellos por razón de mantener una "estabilidad

24. AGUILAR, José Manuel. Con mamá..., op. cit., p. 84 
geográfica”. A través de estas resoluciones, el Alto Tribunal parece operar un giro copernicano en la forma tradicional de entender el interés del menor en la custodia compartida. En última instancia lo que esto implica es que el Tribunal deberá siempre argumentar la razón por la que no otorga la custodia compartida, no siéndole en adelante legitimo alegar simplemente que el interés superior del menor determina mantenerlo siempre en su vivienda, con su madre, salvo que se acredite cumplidamente motivos suficientes para convencer al juzgador de que, en ese concreto caso, procede la custodia compartida.

\subsubsection{La relativa disponibilidad profesional, horarios y actividades de los progenitores: Las posibilidades de conciliación de la vida familiar y laboral de los progenitores}

Nos estamos refiriendo, en definitiva, a la valoración de la disponibilidad de los padres para mantener el contacto y trato físico y directo con los hijos en el periodo alterno correspondiente; las profesiones que exigen viajes y desplazamientos continuos y de cierta permanencia, en principio, no aconsejan la custodia compartida y será preferible fijar un régimen de comunicación y estancia amplio. En efecto, el hecho de que uno de los progenitores viaje de forma constante por motivos de trabajo, puede hacer que la guarda compartida no proporcione al menor la estabilidad necesaria en su día a día, motivo suficiente para desestimar su establecimiento y preferirse un sistema de guarda monoparental con un régimen de visitas adaptado a dicha circunstancia. Así sucede en la SAP Valencia 10 a $^{\mathrm{a}}$ de 31 de marzo de 2004 e igualmente en la más reciente SAP Barcelona 12 a de 11 de diciembre de 2013 que, revocando la custodia compartida fijada en la instancia, establece en interés de la hija común un modelo de guarda materna, con fines de semana alternos de viernes a domingo hasta las 20 horas y un día entresemana con pernocta.

La indisponibilidad de los padres para mantener el trato directo en el periodo correspondiente y la alta dedicación profesional del progenitor, suelen constituir un obstáculo a la fijación del régimen si el otro tiene una ocupación menos absorbente. De este modo, la Jurisprudencia procede a no adoptar la custodia compartida interesada cuando por la profesión del demandado, o por su horario laboral, daría lugar a la imposibilidad física del mismo de hacerse cargo de sus hijos, los días que le correspondiesen (SAP Barcelona 18 ${ }^{a}$ de 18 de julio de 2007, SAP Barcelona 12a de 23 de octubre de 2007, SAP Barcelona 12 a de 27 de septiembre de 2011). Como señalan también los psicólogos ${ }^{25}$, los progenitores, los días en que deben custodiar a sus hijos, tendrán que evitar las reuniones de trabajo interminables y repentinas, los desplazamientos profesionales al otro lado del país o las horas extraordinarias.

Pero, incluso, ante la alegación de un progenitor de que el otro tiene menos tiempo, porque trabaja, debe valorarse la necesidad del trabajo y su fin (más en los tiempos que corren) de modo que éste no debería convertirse en argumento en contra.

En efecto, en no pocas ocasiones los Tribunales valoran que los horarios laborales son un elemento muy importante, y que debe tenerse en cuenta a la hora de fijar el régimen de guarda, pero que, en absoluto pueden ser la causa que necesariamente impida el establecimiento de una custodia compartida, por el hecho de que el menor no pueda pernoctar con uno de los progenitores por su disponibilidad laboral. Así en la SAP Girona 1a de 16 de enero de 2014) se señala que, aún en aquellos casos en los que por cuestiones laborales no fuese posible la pernocta del menor en casa del progenitor, ello no sería un impedimento para el establecimiento de la custodia compartida, pues, estima, lo más importante es el ejercicio compartido de las funciones parentales, sin que sea esencial que tenga que existir una guarda totalmente igualitaria; pues esta puede no serlo $\mathrm{y}$, sin embargo, seguir entendiendo que existe una guarda y custodia compartida. Se valora que más importante que el hecho de que el niño pueda dormir o no con ese progenitor, será que pueda recogerlo en el colegio, llevarlo a realizar actividades extraescolares y deportivas, ayudarlo con los deberes, acompañarlo al médico, prepararle la cena, etc....

También deben dejar de verse como peyorativos el apoyo de los abuelos o de la nueva pareja del progenitor. En el caso de los abuelos, resultan una garantía de buena atención para el

25. POUSSIN, Gerard; LAMY, Anne. op. cit., p. 56 
menor y no hay diferencia alguna con otros niños, cuyos padres conviven y pasan largos espacios de tiempo con ellos. Ahora bien - y conectando este criterio con el anterior-, si se constata en el proceso que existe una conflictiva relación entre uno de los progenitores y los padres del otro progenitor, "la custodia compartida no parece la fórmula idónea para proteger el interés de los menores que es lo que, en definitiva, fundamenta la medida teniendo en cuenta las labores de cuidado y atención que deberán prestarles estos abuelos en razón a la escasa disponibilidad de tiempo por parte del padre por razones laborales" (STS 1․ 15 de octubre de 2014).

\subsection{La relación coetánea y anterior de los progenitores con los hijos: La valoración de la dedicación a la familia coetánea y anterior a la ruptura. El mantenimiento del statu quo y la continuidad como criterio determinante}

Dispone el Art. 92.6 C.C que para acordar cualquier régimen de custodia el Juez tendrá en cuenta, entre otras cuestiones, "la relación que los padres mantengan... con sus hijos". La valoración de esta relación puede ser susceptible de excluir la constitución del régimen de custodia compartida, de la misma forma que determina la atribución de la guarda exclusiva al otro progenitor. Una mala relación de uno de los progenitores con sus hijos es valorada para excluir la custodia compartida en numerosas ocasiones (SAP Madrid 24 a de 5 de marzo de 2007, SAP Las Palmas $3^{a}$ de 26 de julio de 2007, SAP Sevilla $2^{\text {a de }} 10$ de octubre de 2007).

Lo cierto es que en la práctica judicial resulta habitual que el factor determinante para resolver sobre la custodia de los hijos menores sea el criterio de la continuidad o del mantenimiento del statu quo, valorándose la dedicación anterior a la ruptura de los progenitores con relación a los hijos. Ello en la práctica habitualmente viene a suponer que:

a). Aún cuando ambos progenitores presenten igual grado de aptitud y capacidad para el cuidado de los hijos, el progenitor quien antes de la ruptura se hubiera constituido como el cuidador principal o referente del hijo menor y se haya ocupado de una forma primordial del cuidado y atención diaria de los menores, lo seguirá siendo tras la ruptura de la convivencia, atribuyéndosele la custodia en exclusiva, por entenderse que es el progenitor que presenta mayor idoneidad para el cuidado del menor. La dedicación de cada uno de los progenitores a la atención y cuidado del menor antes de la ruptura, la estrechez de los vínculos emocionales y la aptitud personal de cada progenitor, en relación con dicho cuidado, vendrían a ser determinantes a la hora de decidir el modelo de custodia; de modo que el progenitor menos implicado en el cuidado de los menores, durante la convivencia, ni siquiera se plantee solicitar en el proceso una custodia compartida que, de hecho, no ha venido ejerciendo.

b). Si, antes de la ruptura, ambos progenitores acordaron expresa o tácitamente implicarse de manera equivalente en la crianza de los menores -siendo por tanto ambos progenitores igual de aptos e idóneos- tras la separación, ambos, no solo podrían sino que deberían seguir haciéndolo a través de un sistema de custodia compartida (SAP Barcelona 18 ${ }^{a}$ de 7 de octubre de 2010, SAP Barcelona 18 1e $^{\mathrm{a}}$ de abril de 2011). En este sentido, se apunta en la Doctrina. como condición fundamental para el establecimiento de esta custodia compartida. la existencia previa de una situación de paridad entre los cónyuges a nivel de dedicación al cuidado y atención de los hijos ${ }^{26}$. Como sabemos, cuando se habla de paridad, naturalmente, no se está haciendo referencia a igualdad cuantitativa exacta de tiempo material o de estancia física con los menores sino, más bien, de reparto cualitativo de las funciones de cuidado del menor en los momentos lúdicos y escolares, como acertadamente destaca la SAP Barcelona 18 a de 11 de junio de 2013. En la interesantísima SAP Murcia 5a de 26 de junio de 2012, tras desgranar la Jurisprudencia más reciente sobre la materia analiza y ponderar uno a uno des elementos personales y materiales que deben valorarse, se pone de manifiesto que, antes de la crisis conyugal, en los progenitores "existió un alto grado de compromiso con los menores en todas las actividades y decisiones respecto a los mismos" y se enfatiza en que, para apreciar este compromiso en la crianza de los menores, no tiene por qué constatarse que existió un reparto cuantitativo del $50 \%$ del tiempo en la atención de los menores sino en la implicación cualitativa.

26. GUILARTE MARTIN-CALERO,Cristina."Criterios de atribución de la custodia compartida. A propósito de la línea jurisprudencial iniciada con la Sentencia del Tribunal Supremo de 8 de Octubre de 2009", EN: InDret, julio 2010, p. 15. 
Sin embargo, existe cierta polémica en torno al alcance del criterio de la continuidad en el caso de que antes de la ruptura, durante la convivencia no hubiera habido un reparto equitativo, cualitativo $y$ cuantitativo, en el cuidado del menor, y tras la ruptura, el progenitor menos implicado solicite en el proceso la instauración de un sistema de guarda y custodia compartida. Sobre la cuestión existen diferentes posturas:

Para algunos, en estos casos este progenitor no se encontraría "legitimado" o "autorizado moralmente" para solicitar una custodia compartida que no desarrolló mientras convivía en pareja y les sorprenden los casos en los que uno de los progenitores ha desatendido a los menores y cuando se produce la ruptura, defienden a ultranza la custodia compartida. En ocasiones, de manera un tanto despectiva, peyorativa e irónica se suele denominar a esta actitud de uno de los progenitores como "síndrome del padre súbito" o "ataque de padritis".

Para quienes defienden en la Doctrina jurídica que el criterio de la continuidad debe ser decisivo y prevalente ${ }^{27}$, causa extrañeza que se pretenda cambiar el rol después de la separación y se invoque una igual, que nunca existió, y que hubiera conllevado una responsabilidad parental no ejercida a lo largo de años. Cuando hay una situación de igualdad previa, en la asunción de las responsabilidades para con los hijos, la solución posterior a la separación debe ser igualitaria, pero cuando el peso lo ha llevado fundamentalmente uno de los progenitores, el régimen familiar posterior debe tener en cuenta estas circunstancias. Nada hay más injusto que ampararse en la aplicación de la igualdad cuando las situaciones de partida son desiguales.

En esta línea de razonamiento, dentro de la Jurisprudencia, por consiguiente, y a contrario, cuando no existió esta previa implicación parental durante la convivencia, antes de la ruptura, se entiende mal que después de ésta se pretenda ejercer una custodia compartida que no se ejerció antes. En efecto, cuando se solicita la custodia compartida, muchos tribunales están empezando a indicar que este sistema exige que "ambos

27. SANSEGUNDO MANUEL, T, "Maltrato y separación: Repercusiones en los hijos" EN: Custodia compartida y protección de menores, Cuadernos de Derecho Judicial, CGPJ, 2009, p. 144 progenitores hayan compartido las obligaciones y cuidados de los menores constante matrimonio"; este fue uno de los argumentos utilizados por

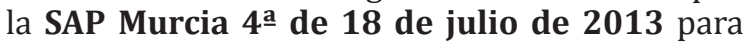
denegar una custodia compartida. La SAP León $\mathbf{1}^{\mathbf{a}}$ de 27 de septiembre de 2013, otorgó la custodia a la madre descartando la custodia compartida, con el argumento de que el hecho de que el padre lleve al niño al colegio y al médico o le haya comprado ropa, no son datos reveladores de que se ocupe de la atención diaria de las necesidades del menor, atención que ha venido estando a cargo de la madre. Por su parte la SAP Barcelona 12 ${ }^{\underline{a}}$ de 27 de septiembre de 2011 estima que en el caso de autos la custodia compartida no procede "pues la compatibilización de la actividad profesional y el cuidado de los hijos debe producirse tanto antes como después de la ruptura de la convivencia para ser creíble como actitud y compromiso de los progenitores". En la SAP Valencia 10 ${ }^{\text {a }}$ de 12 de diciembre de 2012 se reseña que no existe razón objetiva, ni subjetiva, para discrepar del criterio del juzgador de instancia al atribuirle la custodia a la madre, pues se ha implicado en un porcentaje muy superior en las cuestiones diarias de los menores. La SAP Barcelona 12 ${ }^{a}$ de 27 de febrero de 2013 argumenta que la custodia compartida es inviable, en este caso, al quedar probado que, prácticamente desde que nacieron, los hijos han sido cuidados por la madre quien, durante casi los 15 años en los que perduró la convivencia, se ha dedicado al hogar y la familia. Finalmente, la SAP Barcelona 18 ${ }^{\mathrm{a}}$ de 4 de febrero de 2013 estima que no existe motivo alguno para cambiar la rutina de los menores y lo que ha sido hasta la fecha su modo de vida, es decir una madre cuidadora frente a un padre más ausente en la cotidianidad, debiendo recordarse, además, que fueron los propios padre los que configuraron un determi $\neg$ nado tipo de familia.

Es precisamente - en beneficio del menor que ha de procurársele una atención similar a la que recibía antes de la separación para que ésta le afecte lo menos posible. Por demás, en la Doctrina se $\operatorname{argumenta}^{28}$ que establecer judicialmente un sistema de guarda del menor, que no se corresponde con el estilo de vida y la división del trabajo existente durante la convivencia de los progenitores, puede provocar dificultades, precisamente, en aquellas familias en las cuales,

28. GARRIGA GORINA, Margarita. "El criterio de la continuidad frente a la guarda conjunta" EN: InDret 3/2008, p. 5 
antes de la crisis, no se compartían estas tareas de cuidado, pues genera riesgos de inestabilidad al requerir una reestructuración de los roles de los progenitores, quienes se ven abocados a realizar tareas a las que no están habituados y a sacrificar otros objetivos, especialmente los profesionales.

Otro peligro y dificultad palpable podría ser el riesgo de aparición de rechazo por parte del menor; si durante el matrimonio uno de los progenitores no se implicó activamente en el cuidado del hijo menor y, tras la ruptura, se impone judicialmente un sistema de guarda en el que éste se va a ocupar en mayor medida del niño, hipotéticamente puede surgir un rechazo del menor en mayor o menor grado. El riesgo es hipotético porque no tiene que aparecer en todas las familias y va a depender de muchos factores como la edad del menor, tiempo de convivencia en común, grado de colaboración y entendimiento entre los progenitores en relación al menor tras la ruptura, etc. Por ello, en algunos casos, la aparición posterior de ese hipotético rechazo del menor hacia uno de los progenitores, podría hacer fracasar el desarrollo adecuado de la custodia compartida y podría obligar a la modificación de esta medida; bien a través de una graduación y modulación de la custodia compartida, bien a través de la imposición de un sistema de guarda exclusiva con periodos de visitas. Con todo, ello siempre requiere de un exhaustivo seguimiento y estudio por parte de especialistas en psicología, quienes determinaran el verdadero origen, causas y motivaciones de ese hipotético rechazo.

Desde esta óptica se pone especialmente el acento en que, en realidad, la custodia compartida empieza al nacer el hijo, no con el divorcio; por ello, estiman, hay que valorar la "corresponsabilidad" de los progenitores desde el nacimiento del niño, no desde la ruptura de la pareja.

Frente a esta postura, surgen diversas críticas tanto desde el ámbito jurídico como psicológico. De entrada, en la Doctrina, no falta quien pone de manifiesto que el patrón escogido que hace depender el requisito de la idoneidad, para la decisión judicial, de la persona encargada del cuidado habitual de los hijos menores tras la ruptura, suele venir predeterminado por planteamientos ideológicos, algunos de carácter trasnochado, otros retrógrados y reaccionarios, $\mathrm{y}$ que siguen valorando la figura materna como exclusivo referente de apego principal, y a la figura paterna como mero referente periférico. Entienden que ha de superarse esa mentalidad, apostando por planteamientos de auténtica igualdad y paridad en el cumplimiento de las obligaciones domésticas, entre los que resulta principal la de participar, compartir y distribuir el deber de crianza, cuidado y atención de los hijos, siempre que ambos progenitores hayan hecho frente común en el compromiso de asumir esas obligaciones durante la convivencia familiar y muestren una idoneidad y predisposición a seguir asumiéndolas tras la ruptura, al margen de cualquier consideración por razón de sexo ${ }^{29}$.

Desde el campo de la psicología se expone que el reparto de papeles previo a la ruptura y el criterio de la continuidad, no puede tomarse como patrón de comportamiento fijo ni debe constituirse como el criterio decisivo y principal sino que, a pesar de ser una variable importante, también debe tenerse en cuenta la variación radical de circunstancias y condiciones que llevaron a la aceptación de tales roles o funciones por parte de los miembros de la pareja. Es fácilmente observable, se señala, el cambio sustancial que muchos progenitores adoptan implicándose activamente en la crianza de sus hijos, una vez la ruptura ha tomado cuerpo; es evidente que, tras la separación, las circunstancias y condiciones concurrentes han cambiado radicalmente de modo que los progenitores pueden, o quieren, dedicar más tiempo al cuidado de su hijo; un tiempo que antes posiblemente dedicaban a compartir con su ex-pareja. Lo cierto es que, en realidad, abordar adecuadamente la cuestión planteada nos lleva a plantearnos una pregunta de mayor calado: El prevalente principio del interés superior del hijo menor tras la ruptura de sus progenitores ¿excluye la valoración judicial de los intereses de los progenitores? En la Doctrina no faltan autores que responden negativamente a este interrogante estimándose que la idea asentadísima de la consideración primordial del interés del niño no debe descartar la valoración de otros intereses que gravitan en torno a la organización de la vida familiar post-ruptura y, en especial, en cuanto a la atribución del cuidado personal de los $\operatorname{hijos}^{30}$. En esta línea argumentativa puede citarse,

\section{SERRANO CASTRO, Francisco. op. cit., p. 25; AGUILAR, José Manuel,} Con mamá... op. cit., p. 84

30. LATHROP, Fabiola. "Los conflictos de intereses entre progenitores e hijos". EN: Gaceta Jurídica (Santiago, Chile). №. 330 (dic. 2007), p. 3 
en la Jurisprudencia, la SAP Barcelona 12 ${ }^{\mathbf{a}}$ de 1 de octubre de 2013 que estima que el final de la relación, con frecuencia, viene a suponer un punto de inflexión en el que la vida de los cónyuges debe organizarse y adaptarse en todos los ámbitos, incluido el profesional o laboral, de forma que puedan atender todas sus obligaciones, ahora individualmente, sin que nada impida a quien, hasta ese momento, había dedicado menos tiempo al menor, equipararse al progenitor quien, hasta la ruptura, se había ocupado de él en mayor medida.

Por demás, se critica que estos progenitores sean objeto de burla irónica y peyorativa, pues ello no revela sino una Sociedad con una visión estática de los sujetos y sus papeles, independientemente de su voluntad y deseo, y una visión pesimista y conservadora del futuro de la sociedad ${ }^{31}$. En esta línea, se aboga que tales nuevas circunstancias sean tenidas en cuenta por el Juez analizando cada familia, investigando en cada caso concreto si existe ese cambio de circunstancias, así como las motivaciones últimas de la petición de la custodia compartida por parte del progenitor. En efecto, debe tenerse en cuenta que, en muchas ocasiones, durante el matrimonio son ambos progenitores, en atención al tiempo disponible en función de sus circunstancias personales, profesionales y laborales, quienes deciden, pactan y aceptan expresa o tácitamente el reparto de tareas: en definitiva, quién, cuándo, cuánto y cómo dedican el tiempo de atención y cuidado de los hijos. En otras ocasiones, en cambio, puede llegar a detectarse que, en realidad, durante la convivencia hubo una dejación voluntaria de funciones parentales y quizás existan motivaciones espurias en la solicitud de custodia compartida.

Lo cierto es que, en relación con esta polémica, la Jurisprudencia siempre pone el acento, por encima de todo, en el interés superior del menor. En este sentido son muy interesantes las reflexiones contenidas en la SAP Barcelona 18 ${ }^{\underline{a}}$ de 23 de enero de 2014, cuando expresa que si bien se debe partir del modelo de custodia preexistente en la familia, al tiempo de la ruptura, ello no ha de impedir, si el beneficio del hijo lo requiere, adoptar judicialmente otra modalidad de custodia distinta:

Como se ha señalado de forma reiterada por esta Sala, entre otras en Sentencias de

31. AGUILAR. José Manuel. Con mamá... op. cit. p. 84
08/04/2011 y del $04 / 04 / 2013$, el sustrato o denominador común de todos los criterios o factores que se sostienen como favorables al establecimiento de una custodia compartida, no es otro que la estabilidad del menor o de la menor en cada caso concreto y que para ello tiene una importancia fundamental el sistema de vida, la organización familiar y en definitiva la dinámica familiar llevada a cabo hasta el momento en que se plantea la petición, sea ésta la anterior a la ruptura o la posterior a dicha ruptura inmediata a la iniciación del procedimiento.

(...). En el mismo sentido el Tribunal Supremo en Sentencias de 8 de octubre de 2009, 11 de marzo y 1 de octubre de 2010 , ante la ausencia de criterios legales para acordar este tipo de custodia, señala como tales entre otros la práctica anterior de los progenitores en sus relaciones con el menor y sus aptitudes personales y los acuerdos adoptados por los progenitores (negrilla fuera del original).

Añadiéndose a continuación que, no obstante,

(...) el criterio de la continuidad no ha de impedir que se acuerde otra modalidad de custodia, no ha de impedir que se establezca otra organización familiar después de la ruptura, pero para ello debe acreditarse que la nueva organización que se propone resulta beneficiosa para los menores o que no perturba su estabilidad, estabilidad que está vinculada a su forma de vida y a su cotidianeidad (negrilla fuera del original).

\subsection{La edad de los menores}

En la Jurisprudencia, la edad de los hijos sirvió y sirve, en ocasiones, como fundamento para la exclusión de la custodia compartida.

De un lado, ciertos especialistas de la psicología catalogaban, en el pasado, como "nociva" la custodia compartida en niños de corta edad. Esto se conocía como "Tender years Doctrine" (Doctrina de los años tiernos). Se resaltaba el papel de la madre como irremplazable en los primeros años de vida y se considera al padre como una figura secundaria y superflua, defendiendo la necesidad de establecer una edad mínima, como límite, para otorgar la custodia compartida. 
Sin embargo, recientes estudios contradicen lo anterior, alegando que el contacto frecuente (aunque sea corto) es aún más necesario en edades tempranas, en vista que se tiene menos desarrollada la memoria a largo plazo y se corre el riesgo de que haya un retroceso en las relaciones; aún cuando es imposible negar la necesidad biológica que une al menor con su madre.

Ciertamente aquella óptica ha estado vigente en la legislación española, con diversas modalidades, hasta 1990, y no deja de seguirse en la actualidad, junto con la Teoría del "progenitor psicológico principal", en la práctica de muchos Juzgados y Tribunales, implícita o explícitamente.

En la actualidad, en la decisión judicial de la adopción de la custodia compartida no debe de ser determinante la importancia del factor "edad del menor" sino que dicho dato fáctico únicamente debiera ponerse en relación con la elección del sistema de alternancia en la custodia más adecuado: En esta tesitura, debe tenerse en cuenta la premisa de que, a menor edad, menor duración en la alternancia de los progenitores y, a mayor edad, mayo tiempo de alternancia ${ }^{32}$. Siendo esto así, bien puede decirse que, en relación al factor de la edad para un adecuado funcionamiento de la custodia compartida, cuanto más pequeño sea el menor de edad, más complicado o dificultoso (no imposible) será poder adoptar un régimen de custodia compartida, y, por el contrario, cuanto mayor sea, y más si el propio hijo está implicado en sus relaciones con su padre y su madre, más fácil será la custodia compartida. Esto debido a que no son iguales las necesidades de un bebé que las de un adolescente. A modo de ejemplo, si nos referimos a niños de entre 7 y 11 años, se puede decir que se trataría de menores quienes ya tienen una edad en la que pueden colaborar al buen funcionamiento del régimen de custodia compartida, pues se da una cierta estabilidad en sus necesidades, derivada del alcance de una cierta autonomía en sus actividades básicas que permite la asunción de roles personales en descargo de sus padres (referidos a vestido, aseo, comida, etc.) y que, por ello, permiten facilitar una correcta ejecución de la custodia compartida.

32. AGUILAR, José Manuel. Con mamá... op.cit., p. 94.
Ahora bien, y como señalábamos, eso no debe significar, como señalan algunas resoluciones, que la corta edad del menor deba ser un impedimento, por sí mismo, a la instauración del sistema de custodia compartida. La SAP Zaragoza $4^{\text {a }}$ de 15 de octubre de 2003 no encuentra impedimento alguno, a falta de otro dato objetivo de carácter negativo, para que se instaure un sistema de guarda compartida por periodos semanales en relación con una niña de 2 años. En la SAP Barcelona 12 $2^{\mathrm{a}}$ de 21 de septiembre de 2012, el SATAF no excluye la posibilidad del establecimiento de una custodia compartida semanal de un niño de $\mathbf{3}$ años:

(...) considerando que el interés del menor es compartir el máximo tiempo posible tanto con su madre como con su padre, siendo ese régimen el que mejor satisface ese interés. Los tres años de edad de un niño, junto a otras circunstancias favorables que acompañen, pueden ser el momento ideal para un cambio, dado que el menor está entrando en la niñez tras su primera infancia y tiene la capacidad de asimilar cambios moderados en su entorno que potencien las relaciones materno/paterno - filiales anteriores.

Más explícitamente, la SAP Pontevedra $3^{\underline{a}}$ de 19 de junio de 2013 se decantó por la custodia la custodia compartida aun cuando el menor era aún lactante con estos argumentos:

La edad del niño, como denota el informe psicosocial, no es impedi $\neg$ mento, de hecho se destaca que no percibe el conflicto. Con todo lo anterior, lo que recoge el Informe Psicosocial realizado en la alzada viene a ser la capacitación de ambos padres para la custodia y guar $\neg$ da del menor, la convergencia de circunstancias mas que favorables al ejercicio de la custodia compartida, en atención a las residencias y al entorno familiar y social, al poderse mantener todo ello sin maᄀyores repercusiones, resultando además ésta lo mejor para el niño su afectividad y desarrollo, sin constituir la oposición de la madre más que un instinto de sobreprotección que necesariamente ha de superar y sin converger una problemática real por la lactancia o la escolarización del niño. Apreciaciones todas ellas perfectamente compartidas por la Sala, pues todo indica que el acudir a su edad a una guardería pública o privada o el cambio de centro no tiene ma $y$ yor incidencia, de hecho la madre se manifestó claramente en su de $\neg$ claración a favor en su momento de la 
escolarización en la Educación Pública y la lógica y experiencia apuntan a que a esa edad el cambio de guardería, no resulta en absoluto conflictivo, en este caso ni para el niño ni para el entorno al poder mantener el mismo por proximi $\neg$ dad, y todo ello con el apoyo familiar que se destaca a ambos pro genitores. Tampoco la lactancia pues se reconoce por la madre que tiene previsto dejarla al final del Verano, que el pediatra anterior le dijo que la dejara definitivamente ya antes y que el niño ya come de todo, si bien sigue demandando pecho y se lo da como comple $\neg$ mento. Con las anteriores premisas, la crítica de la representación procesal de la madre al informe psicosocial por la cualificación de la técnico social informante no puede compartirse, máxime atendien $\neg$ do a su experiencia, habilitación y razonada exposición de la situa $\neg$ ción estudiada, percepciones y análisis realizados para su revisión y conclusiones.

Algunas corrientes de pensamiento estiman que el argumento según el cual, por la corta edad del niño, resulta conveniente que la responsabilidad de la guarda la ejerza la madre, dado que puede ejercer las funciones parentales mejor que el padre (Doctrina de los años tiernos), responde a un prejuicio social impropio de la realidad que corresponde a la época, situación y entorno social de los padres de hoy en día. Los consejos de la psicología especializada enfatizan precisamente en que, cuanto menor sea la edad del niño, antes se habituará a vivir y desarrollarse en las circunstancias que le han tocado, con un padre y una madre que no conviven y que disponen cada uno de su propio domicilio que comparten con el hijo de manera natural, y sin que se produzcan los traumas propios de las separaciones en niños de edad más avanzada. En reciente SAP Barcelona $12^{\text {a }}$ de 16 de enero de 2013 se enfatiza que invocar exclusivamente la edad de los menores sin justificar la repercusión que la guarda compartida puede suponer para ellas, supone un prejuicio sin base científica alguna. Y más específicamente en la SAP Barcelona $12^{a}$ de 14 de mayo de 2010 se estima que la teoría de que los niños menores de esa edad no deben pernoctar fuera del domicilio materno (pero sí paterno), responde a prejuicios que descansan en la discriminación sexista.

Sobre la cuestión de la edad de los menores y su relación con sus progenitores se debe tener en cuenta la opinión de los especialistas en psicología evolutiva, cuando ponen de manifiesto que el sistema de estancias, que se establezca judicial o convencionalmente. habrá de estar adaptado y acorde con el desarrollo y etapas evolutivas del niño (lactancia, escolarización, autonomía, pre y adolescencia...) las cuales presentan diferentes y especificas necesidades hacia el menor.

Adelantando en parte lo que se dirá más abajo sobre los sistemas de alternancia, el factor edad resultará fundamental respecto de la frecuencia y la extensión de los periodos de alternancia de las estancias: cuanto menor sea el niño más amplia debe ser la frecuencia de contacto con el progenitor no custodio. La norma de aplicación de la custodia compartida implica que, cuanto más pequeños sean los niños, los tiempos de convivencia sean más breves pero más frecuentes. Si se trata de un bebe podrían otorgarse todas las tardes al padre, mientras el resto del tiempo, incluida la mayor parte de las pernoctas, éste permanecerá con la madre; conforme el niño se va haciendo mayor los contactos pueden distanciarse, lo que le evita cambios excesivos. A partir de los 12 años, los periodos pueden ser tan prolongados como años escolares alternos en casa de cada uno de los padres, con el consiguiente régimen de visitas para el progenitor que no reside con el niño. En definitiva, en estos casos, lo relevante para establecer la custodia compartida no debiera ser simplemente la edad del menor sino la adopción de una adecuada alternancia temporal, teniendo en cuenta, precisamente, esa edad, todo ello sin dejar de valorar otros factores, o circunstancias fácticas, que puedan aconsejar (práctica o dedicación anterior a la separación...) o desaconsejar (graves desavenencias entre progenitores, importante distancia entre domicilios, indisponibilidad laboral o profesional...) su establecimiento

3.5. La opinión y voluntad de los menores y el resultado de los informes psicológicos, sociales o médicos.

En la apreciación de los elementos que van a permitir al juez adoptar la medida de la guarda y custodia compartida, cuando no exista acuerdo de los progenitores, tienen una importancia decisiva los informes técnicos, tanto los que el Juez puede solicitar de acuerdo con lo que dispone el Art. 92.9 C.C, como los aportados por las partes.

El informe pericial psicológico emitido por el Equipo Técnico adscrito al Juzgado generalmente, suele proporcionar al juez interesantes elementos de convicción; por ello, en numerosas ocasiones, 
si propone como régimen adecuado la custodia exclusiva o se limita a desaconsejar la custodia compartida, el juez no se aparta de la propuesta. Estos informes, puestos en relación con la audiencia del menor, permiten valorar si resulta adecuada la custodia compartida.

Precisamente, la opinión del menor ha podido, bien, o ser manifestada en la exploración judicial o bien, recogida en los Informes del Equipo Psicosocial adscrito al Juzgado o en cualquier otro Informe de carácter técnico; el sentido de sus deseos puede ser diverso.

Existen una serie de elementos a ponderar a la hora de valorar adecuadamente el deseo expresado por el menor de pasar a convivir con el progenitor no custodio:

a). Es evidente que el primer parámetro a tener en cuenta es la edad del hijo menor; cada etapa evolutiva, dentro de la minoría de edad, tiene sus peculiaridades de madurez y discernimiento.

b). Una segunda variable a ponderar es la posible existencia de presiones o influencias externas, falta de consistencia o justificación de los deseos expresados por el menor. En esta línea, el caso más patológico de la influencia sobre el hijo menor lo constituye la alienación parental, esto es, el influjo sobre los hijos para tratar de desacreditar, inicialmente, y rechazar, finalmente, al otro progenitor frente a los ojos de aquellos y cuya detección resulta hoy posible gracias a los Equipos Psicosociales. En síntesis, los elementos recurrentes a ponderar son: la seriedad y consistencia del deseo y su justificación, puesta en relación el resto de las pruebas, así como el grado de discernimiento en relación con la edad del menor.

Por ello, el Juez debe cerciorarse de que la voluntad del menor haya sido correctamente formada, que el menor no se encuentre condicionado, o presionado, por uno de sus progenitores, o por ambos, y valorar sus opiniones dentro del contexto en el que nos encontramos, es decir, dentro de un procedimiento contencioso en el que el menor puede y suele encontrarse inmerso en un conflicto de lealtades. Tampoco hay que olvidar lo influenciable que puede llegar a ser la voluntad de un menor mediante el ofrecimiento de determinadas ventajas, sobre todo de naturaleza económica o lúdica por parte de los progenitores, lo que no es inhabitual cuando de adolescentes o pre-adolescentes se trata (SAP Asturias 4ํㅗ de 28 de abril de 2010).

c). Finalmente, y no menos importante, consiste en valorar si el interés superior de menor se satisface necesariamente con la nueva medida que se pretende. El Juez debe indagar cuál es el verdadero interés del menor, aquello que le resultará más beneficioso no sólo a corto plazo, sino, lo que es aún más importante, en el futuro. En la búsqueda de lo beneficioso para el menor debe tomarse en consideración que aquello que el niño quiere no es, precisamente - mejor dicho, no tiene por qué ser-, aquello que más le conviene, ni tiene por qué coincidir su opinión con lo que se decida que resulta más adecuado para él mismo, según reiterada doctrina jurisprudencial (SAP Baleares 5a de 29 de junio de 2005, SAP A Coruña 5a de 11 de septiembre de 2006).

Tal como ha declarado nuestra doctrina jurisprudencial, a la hora de sopesar cuál es el interés del menor, el Juzgador ha de valorar de manera discrecional todos los elementos de prueba que se hayan aportado, conjuntamente con la exploración. Por tanto, el deseo del menor no es el único factor que los tribunales deben tener en cuenta para tal fin, debiendo valorarse igualmente los demás medios probatorios, en orden a determinar cuál es la opción que mejor protege el interés superior de aquel.

Bajo las premisas expuestas, cabe reseñar que en numerosas ocasiones la voluntad de los menores y los Informes periciales son elemento de valoración determinante tanto para excluir la custodia compartida (SSAP Madrid 24 ${ }^{\underline{a}}$ de 11 de octubre de 2007; SAP Murcia 1a de 26 de febrero de 2007; SAP Asturias 7ạ de 27 de abril de 2007; SAP Ciudad Real 2a de 20 de abril de 2007; SAP Madrid 22a de 8 de mayo de 2007, SAP Murcia 4 ${ }^{\text {a }}$ de 18 de julio de 2013) como para acordarla (SAP Barcelona 18 ${ }^{\mathrm{a}}$ de 1 de octubre de 2007; SAP Barcelona 12ª de 5 de octubre de 2007).

3.6. Otras circunstancias de carácter negativo o desfavorable: Solicitud de custodia compartida genérica, inviable, incoherente o que parece esconder intereses espurios

La solicitud procesal de atribución de custodia compartida por parte del progenitor debe ser 
precisa, y sobre todo, venir acompañada con la propuesta de una modalidad de su ejercicio que sea viable, posible y sin perjuicio del menor. Como se dice obiter dicta en la STS $1^{a}$ a de 16 de febrero de 2015,

exige concretar la forma y contenido de su ejercicio a través de un plan contradictorio ajustado a las necesidades y disponibilidad de las partes implicadas que integre con hechos y pruebas los distintos criterios y la ventajas que va a tener para los hijos (una vez producida la crisis de la pareja), lo que no tiene que ver únicamente con la permanencia o no de los hijos en un domicilio estable, sino con otros aspectos referidos a la toma de decisiones sobre su educación, salud, educación y cuidado; deberes referentes a la guarda y custodia, periodos de convivencia con cada progenitor; relación y comunicación con ellos y régimen de relaciones con sus hermanos, abuelos u otros parientes y personas allegadas, algunas de ellas más próximas al cuidado de los hijos que los propios progenitores.

Por otra parte, y como se señala desde el campo de la psicología ${ }^{33}$, las motivaciones de los adultos cuando se solicita la custodia compartida suelen ser complejas. Por lo general se tiende a alegar el "interés del hijo", pero en ocasiones existen detrás otros argumentos quizás menos confesables: La solicitud de custodia compartida puede ser una manera de seguir manteniendo una relación estrecha con el otro progenitor, cuando no de pretender continuar ejerciendo "control" sobre la familia o, por qué no decirlo, para tratar de "fastidiar" a la antigua pareja.

Estas y otras motivaciones suelen esconderse, en ocasiones, en las solicitudes de custodia compartida, efectuadas con carácter subsidiario a una custodia exclusiva o a un amplio régimen de visitas, es decir, cuando se utiliza la institución de la custodia compartida como arma o instrumento procesal ("la mejor defensa es el ataque"). Cuando son detectadas dan lugar a la denegación judicial de la solicitud, bien porque se trata de peticiones que se limitan a una mera manifestación absolutamente vaga y genérica, inconcretas y sin la más mínima precisión respecto al posible contenido

33. POUSSIN, Gerard., LAMY, Anne., op. cit. p.59 material de dicha pretensión, o, directamente, de aplicación inviable (SAP Valladolid $\mathbf{1}^{\text {a }}$ de 21 de septiembre de 2006, SAP Albacete $1^{\text {a }}$ de 19 de enero de 2007), o que claramente esconden intereses espurios de carácter económico-patrimonial, como la evitación del pago de pensiones (SAP Baleares $4^{a}$ de 6 de abril de 2011, SAP Málaga 6aㅡ, 24 de mayo de 2012) o la recuperación del uso de la vivienda conyugal (SAP Barcelona 12 a de 25 de julio de 2007, SAP Madrid 24a de 28 de septiembre de 2011). Significativa es la SAP Murcia 4⿳亠丷⿵冂丶 18 de septiembre de 2014 cuando reprocha al padre solicitante de custodia compartida.

Llama la atención que toda la justificación del actor para solicitar la custodia compartida se centre en el tema económico por lo que la señala como un remedio a su falta de recursos para atender los pagos que le impone la sentencia de divorcio, cuando lo que ha de prevalecer en esta materia es el interés superior de los menores y no la comodidad o beneficios patrimoniales de los progenitores. Ninguna referencia se hace a los recursos humanos y materiales que tiene para atender las necesidades de los hijos (...).

Otras veces, resultan incoherentes muchas peticiones de custodia compartida por parte de progenitores quienes, desde que se inició la ruptura convivencial, han venido dando claras muestras de desinterés por el menor. En este sentido, una manifestación patente de ese desinterés es el no pago de las pensiones alimenticias, que acostumbra a ser moneda de uso común entre la ruptura de facto de la pareja, y la existencia de la sentencia judicial que fija las medidas que regulan la vida de la familia tras la crisis matrimonial, sin que sea válida la excusa de que el progenitor no sabía que se tenía que pagar antes, dado que es obvio, y se da por entendido, que los hijos tienen derecho de alimentos a cargo de ambos progenitores en sentido amplio (SAP Barcelona 12 ${ }^{\mathrm{a}}$ de 11 de octubre de 2012).

\section{CONCLUSIÓN}

La custodia compartida se acordará judicialmente una vez valorados todos y cada uno los factores y elementos personales y materiales concurrentes, debiéndose siempre hacer efectiva la protección del interés del menor 
de la mejor manera posible, no el interés de los progenitores, ni como un sistema de premio o castigo al cónyuge por su actitud en el ejercicio de la guarda. Lo cierto es que todo régimen de custodia tiene sus ventajas y sus inconvenientes. Por lo tanto, corresponde al Juez la valoración de los elementos fácticos concurrentes en el proceso para concluir si ha de aplicarse o no la custodia compartida en cada caso concreto, teniendo bien presente que por encima de todos los parámetros, condiciones y factores expuestos no basta con exponer teorías jurídicas y psicológicas sino aplicarlas de manera ecuánime a la realidad, siempre en beneficio del interés superior del menor o los menores involucrados.

\section{BIBLIOGRAFÍA}

\section{LIBROS}

- AGUILAR, José Manuel. Con mamá y con papá, Editorial Almuzara, 2006

- AGUILAR, José Manuel. Tenemos que hablar, Editorial Taurus, 2008

- GARRIGA GORINA, Margarita. "El criterio de la continuidad frente a la guarda conjunta" EN: InDret 3/2008

- GUILARTE MARTIN-CALERO, Cristina. "Comentarios del nuevo Art. 92 C.C". EN: Comentarios a la Reforma de la separación y el divorcio. Ley 15/2005, Lex Nova, 2007

- GUILARTE MARTIN-CALERO, Cristina."Criterios de atribución de la custodia compartida. A propósito de la línea jurisprudencial iniciada con la Sentencia del Tribunal Supremo de 8 de Octubre de 2009", EN: InDret, julio 2010

- IBAÑEZ VALVERDE, Vicente. "El laberinto de la custodia compartida. Claroscuros de un solo nombre con varios significados" EN: Boletín de Derecho de Familia, núms. 40 y 41 , noviembre y diciembre de 2004, El Derecho

- LATHROP, Fabiola. "Custodia compartida y corresponsabilidad parental. Aproximaciones jurídicas y sociológicas". EN: Diario La Ley, № 7206, Sección Doctrina, 29 Junio 2009

- LATHROP, Fabiola. "Los conflictos de intereses entre progenitores e hijos". EN: Gaceta Jurídica (Santiago, Chile). №. 330 (dic. 2007)

- MONTERO AROCA, Juan. "Comentarios al Art. 92. La guarda y custodia compartida".
EN: Separación y Divorcio tras la ley 15/2005, Tirant Lo Blanc, 2007

- PEREZ MAYOR, Adrián. "La entelequia de la custodia compartida o alterna" EN: Revista Jurídica de Cataluña", № 3,2007

- PEREZ UREÑA, Antonio Alberto. "El interés del menor y la custodia compartida”. EN: Revista de Derecho de Familia, no 26, 2005

- POUSSIN, Gerard., LAMY, Anne., Custodia compartida, Espasa práctico, 2004

- RIVERA ALVAREZ, Joaquín. "La custodia compartida impuesta por el Juez:una realidad excepcional en las crisis matrimoniales" EN: Acciones e Investigaciones Sociales, № 1 Ext, 2006

- SANSEGUNDO MANUEL, T, "Maltrato y separación: Repercusiones en los hijos" EN: Custodia compartida y protección de menores, Cuadernos de Derecho Judicial, CGPJ, 2009

- SEISDEDOS MUIÑO, Ana. "Las medidas relativas en los procesos de divorcio y separación matrimonial: primera aproximación al nuevo texto del Código Civil (Ley 15/2005)”. EN: Aranzadi Civil, № 3, 2005

- SERRANO CASTRO, Francisco. "Hacia un nuevo modelo de corresponsabilidad parental". EN: Revista Iuris, Noviembre 2010

- TENA PIAZUELO, Isaac. "La guarda compartida compartida y las nuevas relaciones de familia". EN: Revista Aequalitas, № 18, Enero-junio 2006

- TOME CAMPUZANO, Herminia. "La custodia 
compartida. Doctrina jurisprudencial de las Audiencias Provinciales". EN: Aranzadi Civil, Tomo III, 2004

- VIÑAS MAESTRE, Dolores."Medidas relativas a los hijos menores en caso de ruptura: Especial referencia a la guarda". EN: InDret, julio 2012

\section{PROVIDENCIAS JUDICIALES}

- Sentencia del Tribunal Constitucional

- STC del Pleno no 185/2012, de 17 de octubre de 2012

- Sentencias del Tribunal Supremo

- STS 1a de 25 de junio de 1994

- -------- de 9 de julio de 2002

- ------- de 8 de octubre de 2009

- -------- de 11 marzo de 2010

- ------- de 1 de octubre de 2010

- -------- de 7 de julio de 2011

- ------- de 22 de julio de 2011

- -------- de 7 y 22 de julio de 2011

- -------- de 10 de enero de 2012

- -------- de 9 de marzo de 2012

- -------- de 19 de abril de 2012

- -------- de 29 de abril de 2013

- -------- de 29 de noviembre de 2013

- -------- de 15 de octubre de 2014

- -------- de 16 de octubre de 2014

- -------- de 30 de octubre de 2014

- -------- de 16 de febrero de 2015

\section{SENTENCIAS DE AUDIENCIA PROVINCIAL}

- SAP Zaragoza 4a de 15 de octubre de 2003

- ----- Valencia 10 $10^{a}$ de 31 de marzo de 2004

- ----- Alicante 6 $6^{a}$ de 29 de diciembre de 2004

- ----- Toledo $1^{\text {a }}$ de 2 de febrero de 2005

- ----- Valencia $10^{a}$ de 7 de junio de 2005

- ----- Baleares 5a de 29 de junio de 2005

- ----- A Coruña 5a de 11 de septiembre de 2006

- ----- Valladolid $1^{\text {a }}$ de 21 de septiembre de 2006

- ----- Barcelona $12^{\mathrm{a}}$ de 26 de octubre de
2006

- ----- Zaragoza $4^{a}$ de 14 de noviembre de 2006

- ----- Barcelona $12^{\text {a }}$ de 20 de diciembre de 2006

- ----- Barcelona 12a de 9 de marzo de 2007

- ----- Barcelona 12 a de 25 de julio de 2007

- ----- Barcelona $12^{a}$ de 16 de octubre de 2007

- ----- Madrid 22 a de 16 de octubre de 2007

- ----- Asturias 4⿳亠丷a de 3 de julio de 2008

- ----- Bizkaia 4aㅡ de 31 de octubre de 2008

- ----- Sevilla 2 2 a de 1 de abril de 2009

- ----- Baleares 4aㅡ de 14 de julio de 2009

- ----- Madrid 22 2 de 21 de julio de 2009

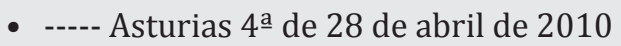

- ---- Barcelona $12^{\text {a }}$ de 14 de mayo de 2010

- ----- Barcelona 18 ${ }^{a}$ de 7 de octubre de 2010

- ----- Barcelona 18 a de 1 de abril de 2011

- ----- Baleares 4aㅡ de 6 de abril de 2011

- ----- Bizkaia 4⿳a de 18 de mayo de 2011

- ---- Girona 1a de 10 de junio de 2011

- ----- Barcelona $12^{\underline{a}}$ de 27 de septiembre de 2011

- ----- Barcelona $12^{\text {a }}$ de 5 de octubre de 2011

- ----- Valladolid 1aㅡ de 22 de diciembre de 2011

- ----- Barcelona 12a de 13 de enero de 2012

- ----- Málaga 6ª , 24 de mayo de 2012

- ----- Murcia 5a de 26 de junio de 2012

- ----- Girona 1a de 27 de julio de 2012

- ----- Barcelona $12^{\text {a }}$ de 21 de septiembre de 2012

- ----- Barcelona $12^{\mathrm{a}}$ de 11 de octubre de 2012

- ----- Barcelona $12^{\text {a }}$ de 30 de noviembre de 2012

- ----- Valencia $10^{\mathrm{a}}$ de 12 de diciembre de 2012

- ----- Valencia $10^{\mathrm{a}}$ de 17 de diciembre de 2012

- ----- Barcelona $12^{\underline{a}}$ de 19 de diciembre de 2012

- ----- Almería 2a de 27 de diciembre de 2012

- ----- Barcelona 12 a de 9 de enero de 2013 